\title{
A transient initiator for polypeptoids post-polymerization $\alpha$-functionalization via activation of thioester group
}

\author{
Solomiia Borova ${ }^{1}$, Christine Schlutt ${ }^{1}$, Joachim Nickel ${ }^{2}$, Robert Luxenhofer ${ }^{1,3}$
}

${ }^{1}$ Functional Polymer Materials, Chair for Advanced Materials Synthesis, Institute for Functional Materials and Biofabrication, Department of Chemistry and Pharmacy, Julius-MaximilansUniversity of Würzburg, Röntgenring 11, 97070 Germany

${ }^{2}$ University Hospital of Würzburg, Department of Tissue Engineering and Regenerative Medicine Röntgenring 11, 97070 Germany

${ }^{3}$ Soft Matter Chemistry, Department of Chemistry and Helsinki Institute of Sustainability Science, Faculty of Science, University of Helsinki, P.O. Box 55, 00014 Helsinki, Finland

*correspondence to: robert.luxenhofer@uni-wuerzburg.de

Keywords: Polypeptoids, ring-opening polymerization, functional initiator, postpolymerization modification, bioconjugation

\begin{abstract}
Here we introduce a post-polymerization modification method of an a-terminal functionalized poly( $N$-methyl-glycine), also known as polysarcosine. We utilized 4-(methylthio)phenyl piperidine-4carboxylate as an initiator for the ring-opening polymerization of $\mathrm{N}$-methyl-glycine- $\mathrm{N}$ carboxyanhydride followed by oxidation of the thioester group to yield an $\alpha$-terminal reactive 4(methylsulfonyl)phenyl piperidine-4-carboxylate polymer. This represents an activated carboxylic acid terminus, allowing straightforward modification with nucleophiles under mild reaction conditions and provides the possibility to introduce a wide variety of nucleophiles as exemplified using small molecules, fluorescent dyes and model proteins. The new initiator yielded polymers with well-defined molar mass, low dispersity and high end-group fidelity, as observed by gel permeation chromatography (GPC), nuclear magnetic resonance (NMR) spectroscopy and matrixassisted laser desorption/ionization time-of-flight (MALDI-ToF) mass spectroscopy. The introduced method could be of great interest for bioconjugation, but requires optimization, especially for protein conjugation.
\end{abstract}




\section{Introduction}

Functional polymers find broad application in the biomedical field. Inter alia, research and application in drug, protein and gene delivery systems [1-18] self-assembled polymers [19-23], nanoreactors [24, 25], bioimaging contrast agent carriers [26], anti-biofouling coatings [13, 2729], sensors [30, 31], tissue engineering [32-34] requires specifically designed polymers with suitable functionalities for appropriate bioconjugation and further biomedical application [3537]. Among the plethora of synthetic polymers, poly(ethylene glycol) (PEG) remains the commercially available "gold standard "for biomedical application due to its high hydrophilicity combined with good solubility in organic solvents [38], low toxicity [39], and stealth behavior [40]. In addition, structural varieties such as star-PEG and a considerable diversity of endgroup functionalization [38, 41-43] are commercially available. Despite PEG being generally regarded safe, antibodies against PEG [44-47] and some other limitations such as toxic side products [48, 49], hypersensitivity [50,51], vacuolization [52-54] and accumulation in the body $[40,54,55]$ were reported. Several studies reported on already pre-existing antibodies in several patients $[56,57]$ during clinical trials with PEGylated therapeutic agents. Hamad et al. demonstrate that depending on PEG concentration and molar mass, unexpected anaphylaxis in some sensitive individual animals could occur [58] after administration with medicines containing a high concentration of PEGylated carriers. Zhang [59] and later Zhao et al. [60] reported on the toxic influence of PEG-modified particles. Accordingly, the search for alternatives has been a going research topic in the chemistry community. Especially, safe alternatives are again of particular interest in the current COVID-19 pandemic considering the allergic reaction and/or anaphylaxis after vaccination with currently developed vaccines [61, 62]. These side effects have been associated with any of the vaccine components, including PEG and PEG derivatives [62, 63]. Among some other polypeptides, polypeptoids, and poly(2oxazoline)s, have been suggested as excellent candidates to substitute PEG [23, 64-67].

Polypeptides and polypeptoids have had significant attention for biomedical application for decades and saw an additional boost in the last few years [68-72]. The absence of hydrogen 
bonds $[73,74]$ in polypeptoids gives them additional advantages like better solubility in various solvents and the formation of stable structures for broad biomedical application $[68,75,76]$. Hydrophilic polysarcosine (PSar) [23, 72] and somewhat lesser hydrophilic poly(N-ethylglycine) (PNEG) $[77,78]$ could be potentially used in the biomedical field. PSar due to nontoxicity $[68,79,80]$, biocompatibility $[64,81]$, non-fouling [82-84], low (or no) cytotoxicity [68, $72,80,85]$, electroneutrality [86] is considered as promising alternative to PEG $[10,87]$.

PSar is most commonly prepared via nucleophilic living ring-opening polymerization (NuLROP) of $N$-substituted $\alpha$-amino acid- $N$-carboxyanhydrides (NNCAs) $[88,89]$, which can be initiated with a variety of nucleophiles. Most commonly, amines are employed [90-92] , but water [92], alcohol [93-95], thiols [96] and others [70, 92, 97-100] have been reported. Notably, PSar and other polypeptoids can also be obtained by NuLROP from the more stable $N$-substituted $\alpha$ amino acid- $N$-thiocarboxyanhydrides (NNTAs) [101, 102]. Apart from determining the polymer chain length via $[\mathrm{M}]_{0} /[\mathrm{l}]_{0}$, an initiator can be chosen to introduce specific functional groups in the a-terminus of the polymers. However, it is important to consider that the introduced functionalities must be compatible with the polymerization process. Only a few papers introduced functional initiators for NCAs polymerization. Tao et al. reported on ROP of Nsubstituted glycine $\mathrm{N}$-thiocarboxyanhydride with cysteamine with a further application for thiolene and thiol-yne click chemistry [103]. Later, Johann and co-workers introduced the aminofunctional trans-cyclooctenes (TCO) and 6-methyl-tetrazine $(\mathrm{mTz})$ as initiators to obtain functional polypeptoids and performed their post-polymerization modification [104]. Postpolymerization modification (PPM) can help to overcome limitations that occur during polymerization and introduce responsive, structural and functional properties into polymers, which are otherwise incompatible with the polymerization process [36, 105-108]. PPM can offer several advantages. On one hand, a variety of different functionalities can be introduced into the side chain or termini of a polymer. On the other hand, the resulting polymer will have the same degree of polymerization and chain length distribution as the original polymer. PPM also allows the synthesis of polymers with functionalities that can not or only inconveniently be introduced directly via the polymerization. 
Different post-polymerization concepts like modification of polymeric active esters, anhydride, isocyanates, oxazolones, epoxides, Michael-type addition reactions, modification by thiol exchange, etc., have been reported for functionalization of polymers [36]. PPM used for bioconjugation, in particular, should offer high efficacy under mild conditions. In the last two decades, click-chemistries have had a major impact in the field of bioconjugation [109]. Despite the preference for PPM utilizing click chemistry, the activated ester exchange reaction still has some value.

The PPM via polymeric active esters became an attractive tool after the first introduction by Jatzkewitz [110-112] and later picked up by Ferruti et al. [113] and Ringsdorf et al. [114]. The reaction of activated esters with amines leads to the formation of stable amide bonds which are of course most common in biological systems. Additionally, there is no need to use of potentially toxic (metal) catalysts or other chemical reagents making them an attractive material in biomedical research [115]. Apart from alkyne-azide click chemistry [116-121], sulfur-based chemistries have been widely exploited [122-126]. Thiol moieties exhibit a favorable low $\mathrm{pK}_{\mathrm{a}}[127,128]$, have ability to form disulfide bonds upon oxidation [129, 130], show a good reactivity profile [131] and are abundant in biological systems [132]. The versatility of sulfur-based chemistry and the ease of modification makes it an attractive choice in organic chemistry and life science [133-135]. A multitude of chemoselective reactions utilizes sulfur chemistry [135-138] with application in many fields, including self-healing materials or drug delivery systems $[122,139]$. One particular thiol-based reagent, 4-(methylthio)phenol (4MTP), has been described long ago for peptide coupling, but to date, has not been investigated for PPM bioconjugation. Johnson et al. reported on the use of 4MTP esters as a carboxyprotecting group during polypeptide synthesis in 1968. When 4MTP is oxidized to yield 4(methylsulfonyl)phenyl $\left(4 \mathrm{MTO}_{2} \mathrm{P}\right)$, it transforms a protected ester into an activated activate ester, allowing further aminolysis and amide formation [140-142]. Chen introduced 4MTP esters for quinoxaline antibiotic synthesis [143]. Later, Siemens applied activated 4MTP esters during peptide solid-phase synthesis [144]. Cho also reported on the application of 4MTP moieties as a safety-catch protecting group during peptide coupling or as an active ester that 
can act with other $\mathrm{N}$-free peptide fragments to form new bonds [145]. More recently, Popovic' et al. reported on peptide 4MTP ester synthesis suitable for peptide segment coupling or direct amidation with peptide N-termini [146]. However, to the best of our knowledge, 4MTP has not been utilized or suggested for any PPMs.

Here, we introduce 4-(methylthio)phenyl piperidine-4-carboxylate (4MTPPC) as a novel functional initiator for the NuLROP of NCAs, in particular N-phenyloxycarbonylsarcosine (PocSar), which forms Sar-NCA in situ $[147,148]$. The oxidation of the 4MTPPC into a $4 \mathrm{MTO}_{2} \mathrm{PPC}$ transforms the protected carboxylic acid into an activated acid which then readily reacts with nucleophiles (Figure 1).

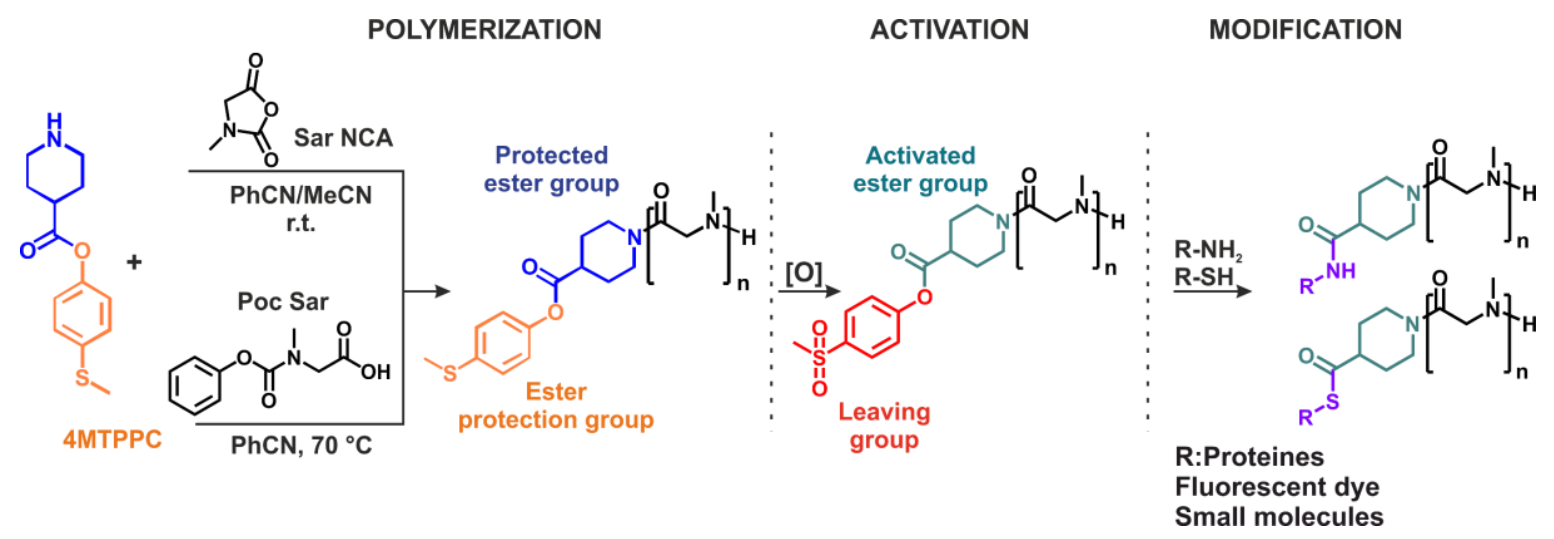

Figure 1. Post polymerization modification concept based on ring-opening polymerization of $N$-phenoxycarbonylN-methylglycine (Poc Sar) and/or N-methylglycine-N-carboxyanhydride (Sar NCA) with 4-(methylthio)phenyl piperidine-4-carboxylate (4MTPPC) initiator via activation of 4(methylthio)phenol (4MTP) ester group. 


\section{Experimental Section}

\section{Materials and methods}

Materials. Dichloromethane (DCM), N, N-dimethylformamide (DMF), N-methyl morpholine (NMP), 1-(tert-butoxycarbonyl)piperidine-4-carboxylic acid (Boc-Inp-OH), trifluoroacetic acid (TFA), 4-(dimethylamino)-pyridine (DMAP), diphenylcarbonate (DPC), 3-chloroperoxybenzoic acid ( $m$-CPBA ), hexane, ethyl acetate (EtOAc), ethanol (EtOH), 4-(methylthio)phenol (4MTP), sarcosine (Sar) was purchased from Sigma Aldrich or TCl and used without further purification. DCM was dried over $\mathrm{CaCl}_{2}$ before further use. TEA was dried over $\mathrm{BaO}$ and distilled before use.

Methods. NMR spectra were recorded on a Fourier $300\left({ }^{1} \mathrm{H} ; 300.12 \mathrm{MHz}\right)$, Bruker Biospin (Rheinstetten, Germany) at $298 \mathrm{~K}$. The spectra were calibrated to the signal of residual protonated solvent $\left(\mathrm{CDCl}_{3}: 7.26 \mathrm{ppm}, \mathrm{D}_{2} \mathrm{O}: 4.79 \mathrm{ppm}, \mathrm{CD}_{3} \mathrm{CN}: 1.94 \mathrm{ppm},\left(\mathrm{CD}_{3}\right)_{2} \mathrm{SO}: 2.50 \mathrm{ppm}\right)$. Gel permeation chromatography (GPC) was performed on a Polymer Standard Service (PSS, Mainz, Germany) system (pump mod. 1260 infinity, RI-detector mod. 1260 infinity, precolumn GRAM $10 \mu \mathrm{M}(50 * 8 \mathrm{~mm})$ ), with HFIP (containing $3 \mathrm{~g} / \mathrm{L}$ potassium trifluoroacetate (KTFA)) as eluent and calibrated against PEG standards. Column was kept at $40^{\circ} \mathrm{C}$ and the flow rate was set to $0.7 \mathrm{~mL} / \mathrm{min}$. Before each measurement, samples were filtered through $0.2 \mu \mathrm{m}$ PTFE filters (Rotilabo, Karlsruhe).

Matrix-assisted laser desorption/ionization time-of-flight (MALDI-ToF) mass spectra were recorded on a Daltonics autoflex II LRF 50 or a Daltonics UltrafleXtreme (Bruker, Bremen, Germany) using an $\mathrm{N}_{2}$ laser $(\lambda=337 \mathrm{~nm})$. All spectra were recorded in positive reflector mode. Detection was typically set from $1000 \mathrm{~m} / \mathrm{z}$ to $7000 \mathrm{~m} / \mathrm{z}$. After parameter optimization, the instrument was calibrated with $\mathrm{Csl}_{3}$ or PEG standards depending on the $\mathrm{m} / \mathrm{z}$ range of the individual sample. Samples were prepared with a-cyano-4-hydroxycinnamic acid or with sinapinic acid as matrices, using the dried-droplet spotting technique (0.5-1.5 $\mu \mathrm{L})$. Exemplarily, samples (1 g/L) were dissolved in $\mathrm{MeOH}$ (supplemented with $1.0 \%$ TFA) or in MeCN. Laser 
power was set slightly above the threshold, typically at 50\%-70\%. Poisson distributions were calculated using eq 1 :

$$
P(D P)(X=k)=\frac{D P^{k}}{\mathrm{k} !} e^{(-D P)}
$$

The Mn, Mw were calculated using eq. 2 from peak analysis obtained from MALDI-ToF experimental data:

$$
M_{n}=\frac{\Sigma N_{i} M_{i}}{\Sigma N_{i}} \quad M_{w}=\frac{\Sigma N_{i} M_{i}^{2}}{\Sigma N_{i} M_{i}}
$$

where $\mathrm{N}_{\mathrm{i}}$ and $\mathrm{M}_{\mathrm{i}}$ are the abundance and mass of the i-th oligomer, respectively.

Ultraviolet-visible (UV-Vis) spectrum was taken on a Jasco V-630 spectrometer in $\mathrm{MeOH}$ in a quartz cuvette $(0.1$ or $1.0 \mathrm{~cm})$. The concentration of the dye was calculated by UV-Vis spectroscopy in an absorption maximum of $325 \mathrm{~nm}$.

The polymers were purified via dialysis. Dialysis was performed using Spectra/Por membranes with a molecular weight cutoff (MWCO) of 1 and $10 \mathrm{kDa}$ (material: cellulose acetate) obtained from neoLab (Heidelberg, Germany) against water (Millipore).

Fast protein liquid chromatography (FPLC) was carried out on an Äktaavant (GE Healthcare, Chalfont St. Giles, Great Britain) to analyze resulting PSar conjugates. A GL 10/300 Column (300 mm, $\varnothing 10 \mathrm{~mm}$, GE Healthcare) was packed with Superdex 75 resin under constant pressure. The purification was conducted in $10 \mathrm{mM}$ TRIS buffer with $300 \mathrm{mM}$ of $\mathrm{NaCl}(\mathrm{pH}=$ 8.0) with a linear flow of $0.5 \mathrm{~mL} / \mathrm{min}$.

Sodium dodecyl sulfate-polyacrylamide gel electrophoresis (SDS-PAGE) was used to analyze protein-polymer conjugates on $12 \%$ PAGE under non-reducing conditions, using standard molecular biology technique. After electrophoresis gels were stained using Coomassie brilliant blue R250. In case of RFP conjugates fluorescent bands were detected using a FluorChem Q imaging system (Biozym).

\section{Synthetic procedures}

Monomer synthesis. Sarcosine NCA. 
The Sarcosine NCA was synthesized as was described previously [149]. Sarcosine $5.00 \mathrm{~g}$ ( $0.056 \mathrm{~mol}, 1.7$ eq.) pre-dried by azeotropic distillation with toluene was placed in $250 \mathrm{~mL}$ dried Schlenk flask and suspended in $90 \mathrm{~mL}$ of dry THF under a steady flow of argon followed by the addition of $4.0 \mathrm{~mL}(0.033 \mathrm{~mol}, 1.0$ eq.) diphosgene via syringe. The continuous flow of argon was turned off, and the reaction mixture was heated to $66^{\circ} \mathrm{C}$. The reaction vessel was equipped with a washing bottle containing $35 \mathrm{wt}$ \% $\mathrm{KOH}$ solution to neutralize the developing $\mathrm{HCl}$. Stirring and heating were continued until all solid was dissolved, and the dark brown solution was obtained (around $3.0 \mathrm{~h}$ ). The solvent was evaporated under reduced pressure, yielding a brownish oil as a crude product. $5.0 \mathrm{~mL}$ of dry petrol ether was added to the obtained product under a steady argon flow and left in the fridge overnight to solidify. The solid was decanted under an argon atmosphere, dried under reduced pressure, and subsequently sublimated in vacuo $(4.00 \mathrm{~g}, 80 \%)$.

${ }^{1} \mathrm{H}$ NMR $\left(300 \mathrm{MHz} ; \mathrm{CDCl}_{3}\right): \delta=3.04 \mathrm{ppm}\left(3 \mathrm{H}, \mathrm{s}, \mathrm{CH}_{3}-\right), 4.12 \mathrm{ppm}\left(2 \mathrm{H}, \mathrm{s},-\mathrm{CH}_{2}-\mathrm{CO}-\right)$.

Synthetic of Poc-Sar.

The synthesis procedure was performed as follows [148]. Sarcosine $50 \mathrm{~g}$ (0.56 mol, $1.0 \mathrm{eq}$.

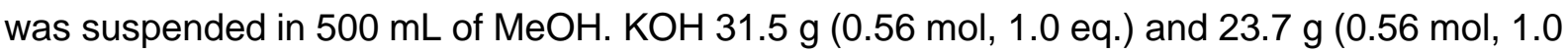
eq.) $\mathrm{LiCl}$ was dissolved in $300 \mathrm{~mL}$ of $\mathrm{MeOH}$ and added to sarcosine suspension. Diphenylcarbonat (120 g, (0.56 mol, 1.0 eq.) was dissolved in $200 \mathrm{~mL}$ of THF, and the rest of the DPC was washed with an additional $200 \mathrm{~mL}$ of THF. The reaction flask was left to react for 7-9 days at room temperature. Subsequently, the reaction mixture was filtered, and volatiles was removed under reduced pressure. The residue was dissolved in $400 \mathrm{~mL}$ of $5 \% \mathrm{NaHCO}_{3}$ and extracted three times with $300 \mathrm{~mL}$ of ethyl acetate (EtOAc). The water phase was adjusted to $\mathrm{pH}$ 3-4 with concentrated $\mathrm{HCl}$ and extracted three times with $300 \mathrm{~mL}$ of EtOAc. The organic phase was dried under $\mathrm{Na}_{2} \mathrm{SO}_{4}$ overnight. The solvent was removed under reduced pressure, and the high viscous gel was obtained as the raw product. The yield of the obtained product is $37.6 \%(44.1 \mathrm{~g})$. 
${ }^{1} \mathrm{H}$ NMR $\left(300 \mathrm{MHz} ; \mathrm{CDCl}_{3}\right): \delta=3.01-3.24 \mathrm{ppm}\left(3 \mathrm{H}, \mathrm{s},-\mathrm{CH}_{3}\right), 4.09-4.25 \mathrm{ppm}\left(2 \mathrm{H}, \mathrm{d},-\mathrm{CH}_{2}-\mathrm{N}-\right.$ ), 7.04-7.42 ppm (5 H, m, aromatic ring). $\left.{ }^{13} \mathrm{C} \mathrm{NMR} \mathrm{(300MHz;} \mathrm{CDCl}_{3}\right): \delta=36.4 \mathrm{ppm}(1 \mathrm{C}, \mathrm{N}-$ $\mathrm{CH}_{3}$ ), 50.81 ppm (1 C, $\left.\mathrm{CH}_{2}-\mathrm{N}-\right), 121.9$ ppm (2C, phenol ring), 125.8 ppm (1C, phenol ring), 129.5 ppm (2C, phenol ring), 151.3 ppm (1C, phenol ring), 155.84 ppm (1C, N-C(O)-O-), 174.45 ppm (1C, C(O)-O-).

Synthesis of 4-(methylthio)phenyl piperidine-4-carboxylate (4MTPPC)

Boc-Inp-OH (2.01 g $8.75 \mathrm{mmol}, 2.0$ eq.) was dissolved in $60 \mathrm{~mL}$ of chloroform and treated with DCC (1.80 g $8.75 \mathrm{mmol}, 2.0$ eq.) for $15 \mathrm{~min}$. Subsequently, 4MTP (0.61 g $4.37 \mathrm{mmol} 1 \mathrm{eq}$.) was added followed by DMAP ( $0.107 \mathrm{~g} 0.874 \mathrm{mmol} 0.2 \mathrm{eq}$.) and 4-methyl morpholine (0.885 $\mathrm{g} 8.75 \mathrm{mmol} 2 \mathrm{eq}$.). The mixture was left to react at room temperature for $5.0 \mathrm{~h}$. The reaction solution was further treated with $18 \mathrm{~mL}$ of TFA for $30 \mathrm{~min}$ at room temperature to remove the Boc protecting group. The crude product was obtained by double precipitation from cold diethyl ether and dry dried under vacuum. $(0.93 \mathrm{~g}, 3.7 \mathrm{mmol}, 93 \%)$. The yield of the obtained product is $93 \%(0.93 \mathrm{~g})$.

${ }^{1} \mathrm{H}$ NMR $\left(300 \mathrm{MHz}, \mathrm{D}_{2} \mathrm{O}\right) \delta=7.42 \mathrm{ppm}(2 \mathrm{H}, \mathrm{d},-\mathrm{CH}=), 7.14 \mathrm{ppm}(2 \mathrm{H}, \mathrm{d},-\mathrm{CH}=), 3.62-3.33$ ppm (2H, m, $\left.-\mathrm{CH}_{2^{-}}\right), 3.33-3.00$ ppm (1H, m, $\left.-\mathrm{CH}_{2^{-}}\right), 2.53 \mathrm{ppm}\left(3 \mathrm{H}, \mathrm{s}, \mathrm{CH}_{3}-\mathrm{S}-\right), 2.37 \mathrm{ppm}(2 \mathrm{H}$, m, $\left.-\mathrm{CH}_{2}-\right), 2.20-1.88 \mathrm{ppm}\left(2 \mathrm{H}, \mathrm{m},-\mathrm{CH}_{2}-\right) .{ }^{13} \mathrm{C} \mathrm{NMR}\left(300 \mathrm{MHz} ; \mathrm{CD}_{3} \mathrm{CN}\right): \delta=15.06 \mathrm{ppm}(1 \mathrm{C},-$ S- $\left.\mathrm{CH}_{3}\right), 24.23$ ppm (2C, $-\mathrm{CH}_{2}$ - piperidine), 37.93 ppm (1 C, - $\mathrm{CH}$ - piperidine), 42.75 ppm (2C, $\mathrm{CH}_{2}$ - piperidine), $127.15 \mathrm{ppm}(2 \mathrm{C},-\mathrm{CH}=$ aromatic ring), $127.40 \mathrm{ppm}(2 \mathrm{C},-\mathrm{CH}=$ aromatic ring), 147.97 ppm (1 C, (O)-O-C- aromatic ring), 172.98 ppm (1C, -O-C $(\mathrm{O})), 136.1$ ppm (1C, $-\mathrm{S}-\mathrm{C}=$ aromatic ring).

\section{Synthesis of PSar.}

The synthesis of PSar was adapted from literature [92] and [94, 95].

\section{Polymerization of Sar-NCA.}

The monomer solution was prepared in a dried Schlenk flask under an inert atmosphere by dissolving Sar-NCA (1.47 g $13.03 \mathrm{mmol}$; 96.5 eq.) and 4MTPPC (0.034 g $0.135 \mathrm{mmol}, 1.0 \mathrm{eq})$ 
in $5 \mathrm{~mL}$ of $\mathrm{PhCN}$ and $3 \mathrm{~mL}$ of $\mathrm{MeCN}$. The reaction solution was stirred under an inert and dry atmosphere at room temperature for $24 \mathrm{~h}$. In the first $2.0 \mathrm{~h}$, a vial was opened to reduce $\mathrm{CO}_{2}$. PSar was purified by precipitation (3x) from cold diethyl ether (re-dissolved in DCM) and lyophilized.

\section{Polymerization of Sar-NCA from Poc-Sar.}

The same procedure was performed with Poc-Sar. Poc-Sar (0.6 g $2.87 \mathrm{mmol}, 50$ eq.) and 4MTPPC (0.0185 g $0.074 \mathrm{mmol}, 1.0$ eq.) was dissolved in $4 \mathrm{~mL}$ of $\mathrm{PhCN}$ and $2 \mathrm{~mL}$ of $\mathrm{MeCN}$. After the initiator and monomer were dissolved, $0.4 \mathrm{~mL}(0.29 \mathrm{~g} 2.87 \mathrm{mmol}, 50$ eq.) of TEA was added, and the reaction solution was heated up to $70^{\circ} \mathrm{C}$ and left to react for $24 \mathrm{~h}$. The pure polymer was obtained by precipitation (3x) from cold diethyl ether (re-dissolved in DCM).

\section{Oxidation of PSar.}

The oxidation of PSar was performed according to the procedure described [96]. PSar (0.142 g, $0.0596 \mathrm{mmol}, 1.0$ eq.) was dissolved in $5 \mathrm{~mL}$ dry $\mathrm{DCM}$ and cooled to $0^{\circ} \mathrm{C}$ in an ice bath. $\mathrm{m}$ CPBA (0.021 g $0.119 \mathrm{mmol}, 2.0$ eq.) was dissolved in $3 \mathrm{~mL} \mathrm{DCM}$, added dropwise to the polymer solution and stirred for $3.0-5.0 \mathrm{~h}$ while warming to room temperature. The resulting polymer was twice precipitated from cold diethyl ether and dried under vacuum with the following dissolution in water and lyophilization to give the white powder $(0.128 \mathrm{~g}, 89 \%)$.

${ }^{1} \mathrm{H}$ NMR $\left(300 \mathrm{MHz}, \mathrm{CDCl}_{3}\right) \delta=7.99 \mathrm{ppm}(2 \mathrm{H}, \mathrm{d},-\mathrm{CH}=), 7.32 \mathrm{ppm}(2 \mathrm{H}, \mathrm{d},-\mathrm{CH}=), 3.62-3.33$ ppm (2H, m, - $\left.\mathrm{CH}_{2-}\right), 3.33-3.00$ ppm (2H, m, $\left.-\mathrm{CH}_{2^{-}}\right), 3.07$ ppm (3H, s, $\left.\mathrm{CH}_{3}-\mathrm{SO}_{2^{-}}\right), 2.37$ ppm $\left(2 \mathrm{H}, \mathrm{m},-\mathrm{CH}_{2^{-}}\right), 2.20-1.88 \mathrm{ppm}\left(2 \mathrm{H}, \mathrm{m},-\mathrm{CH}_{2}^{-}\right)$.

\section{Functionalization of PSar.}

A substitution was performed as follows. Oxidized PSar was dissolved in $5 \mathrm{~mL}$ DCM (or any other suitable solvent) and stirred with 3.0 eq. of nucleophile overnight. A pure product was obtained by precipitation from cold diethyl ether followed by dialysis and lyophilization. 


\section{Results and discussion}

\section{Synthesis of 4MTPPC- functionalized polysarcosine}

This work presents a synthetic pathway to obtain 4MTPPC-functionalised polypeptoids via NuLROP using a new 4MTP-functionalized initiator. As was already mentioned, the presence of a 4MTP group in the a-position of the polymer should allow the subsequent introduction of diverse functionalities via post-polymerization nucleophilic substitution.

Previous work by Chan et al. suggests that it is possible to initiate ROP of NCAs or NNCAs with alcohols [94]. In their contribution, $N$-Butylglycine $N$-carboxyanhydride was employed as a monomer. However, the authors found that phenol proved challenging for this purpose. Nevertheless, we investigated 4-(methylthio)phenol (4MTP) to initiate the ROP of Sar-NCA and Poc-Sar. In line with the results by Chan et al., this approach proved not satisfactory. PSar obtained from Poc-Sar and initiated with 4MTP in PhCN had a higher molar mass than expected from $[\mathrm{M}]_{0} /[\mathrm{l}]_{0}(16.2 \mathrm{~kg} / \mathrm{mol}$ vs. $3.7 \mathrm{~kg} / \mathrm{mol})$ and a broad molar mass distribution $(\boxminus=$ 2.03). The molar mass of polymers obtained from Sar-NCA and 4MTP was also too high, and GPC traces were bimodal. These issues may be attributed to poor initiation efficiency and/or slow initiation. Chan et al. suggest that adjusting the type of alcohol, solvent and base can lead to more satisfactory results, however, our strategy relies on the 4MTP moiety. Also, polymerization in $\mathrm{CHCl}_{3}$ or $\mathrm{MeCN}$ did not show significant improvement. The molar masses of the obtained PSar remain higher than expected (5.1, 5.0 and $2.1 \mathrm{vs} .1 .6 \mathrm{~kg} / \mathrm{mol})$. The dependence of the reaction rate on the nature of the solvent was characterized by NMR spectroscopy. ${ }^{1} \mathrm{H}$ NMR analysis shows presence of significant amounts of diketopiperazine dimer $\left(12 \%\right.$ in $\mathrm{MeCN}, 27 \%$ in $\mathrm{PhCN}$ and $35 \%$ in $\mathrm{CHCl}_{3}$ ) formed during the polymerization (supporting information, Figure SI 1). The presence of a variety of chains suggests that the propagating amine is capable of attacking the ester group in the a-position of the polymer chain end and forming a diketopiperazine dimer or higher molar mass cyclic polypeptoids (Figure 2). The nature of solvent has a significant influence on the polymerization behavior, as evidenced by the different amounts of formed diketopiperazine dimers found in the introduced solvents. 
In $\mathrm{CHCl}_{3}$, monomer consumption was fastest and a markedly higher proportion of cyclic dimer was observed compared to the reactions carried out in MeCN and PhCN. MALDI-ToF mass spectrometry of the product obtained from $\mathrm{CHCl}_{3}$ confirmed low molar mass. Unfortunately, the desired product (MTP-initiated PSar) and the macrocyclic PSar have an identical $\mathrm{m} / \mathrm{z}$ ratio and virtually the same isotope pattern, and therefore we cannot distinguish the two by mass spectrometry (supporting information, Figure S1 and S2). The signal attributed to PSar initiated

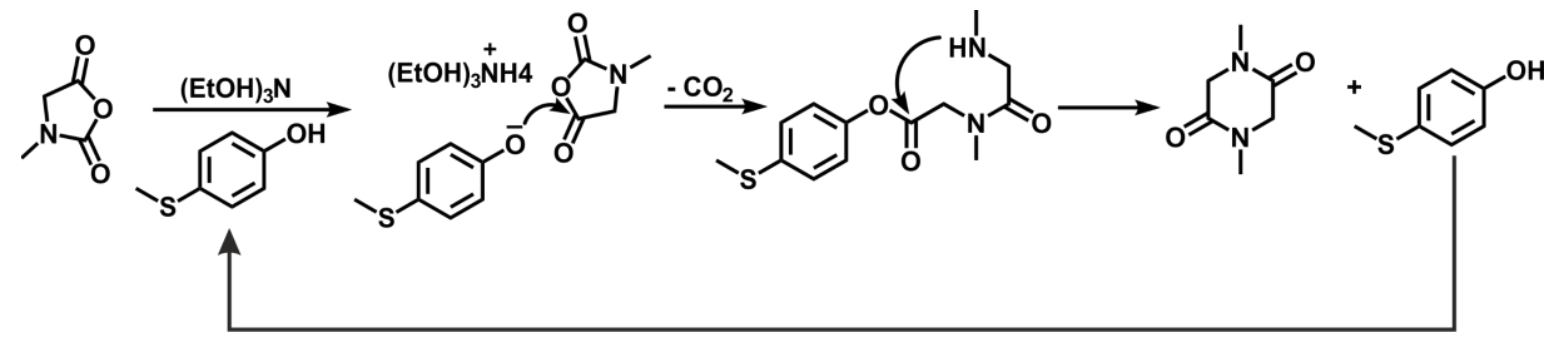

Figure 2. Hypothetic mechanism illustration the formation of cyclic dimers during polymerization with 4(methylthio)phenol.

with 4MTP was observed. However, the presence of low molecular weights cyclic polypeptoids or dimers could not be determined. Interestingly, the obtained signals could also be assigned to oxidized or partly oxidized PSar initiated with 4MTP even though any oxidation was performed. In addition, MALDI-ToF MS data corroborate the molar mass values obtained by GPC (supporting information, Figure S3)

Therefore, we investigated a different strategy, i.e., synthesis of an initiator that contains 4MTP but initiates the ROP through a more reliable nitrogen nucleophile (Figure 3a) and prevents dimer formation at the same time.

While commonly secondary amines are not considered good nucleophiles (they are more basic in character), piperidine and its derivatives are good nucleophiles due to cyclic restraint.

Accordingly, 4-(methylthio)phenyl piperidine-4-carboxylate (4MTPPC) was successfully synthesized in two steps. In the first step, we performed the esterification of Boc-Inp-OH with 4MTP, followed by TFA treatment to remove the Boc group in a second step (Figure 3a). The product was obtained as a white powder with a good yield (93\%) and satisfactory purity. ${ }^{1} \mathrm{H}-$ NMR spectra analysis of the novel initiator in $\mathrm{CDCl}_{3}$ shows the characteristic signal of the methyl group of the thioether (2.48 ppm, blue) and aromatic protons (7.29 and $7.01 \mathrm{ppm})$ of 
4MTP, (Figure 3b). The signal attributed to the 4MTP methyl group (signal 1, blue) is shifted slightly to higher ppm values due to the introduced ester group. Signals 4 and 6 (blue and green, respectively) are represented with two peaks that most likely arise from the axial and equatorial chair conformation of the piperidine group [150, 151].
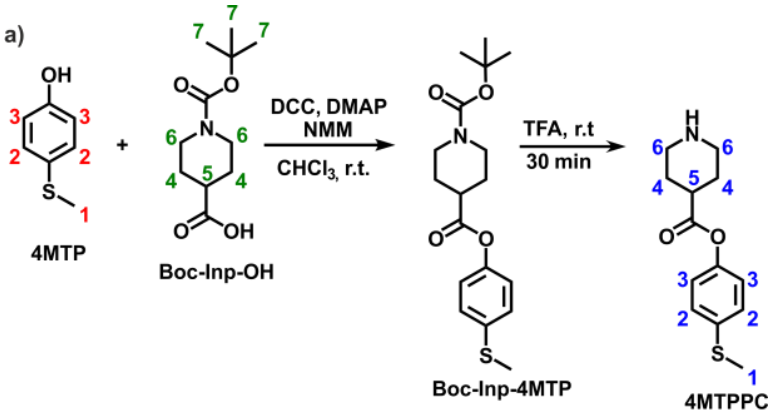

b)

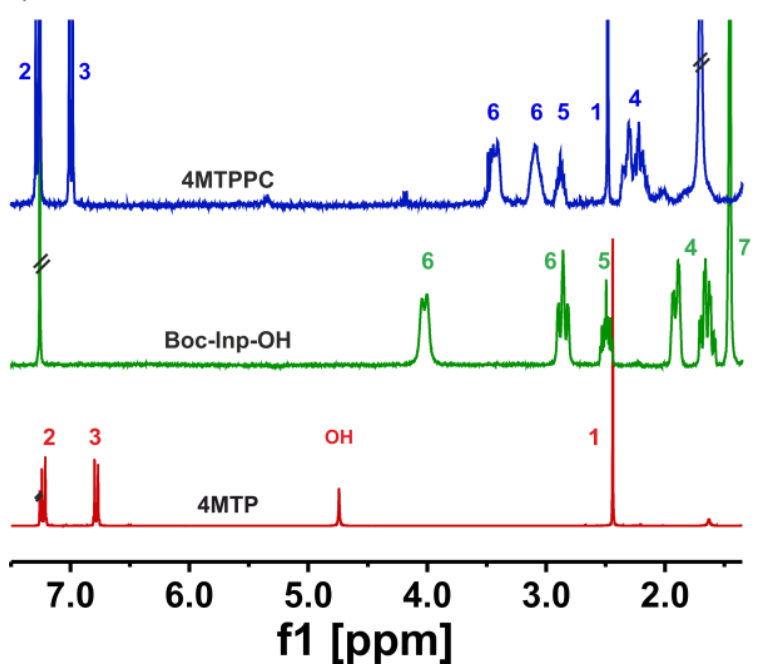

Figure 3. a) Synthetic scheme for the synthesis of 4-(methylthio)phenyl piperidine-4-carboxylate (4MTPPC) by esterification of $\mathrm{N}$-Boc-isonipecotic acid with 4-(methylthio)phenol. b) ${ }^{1} \mathrm{H}$ NMR $\left(300 \mathrm{MHz}, \mathrm{CHCl}_{3}, 297 \mathrm{~K}\right)$ spectra of 4-(methythio)phenyl (red), 1-(tert-butyloxycarbonyl)piperidine-4-carboxylic acid (green) and 4(methylthio)phenyl piperidine-4-carboxylate (blue). 
The synthesis of polysarcosine was performed by ROP of Sar-NCA monomer according to a well-known method [148, 149]. In contrast to initiation using 4MPT initiation, this approach proved successful. NMR spectra analysis of the resulting polymers shows significant signals attributed to PSar initiated with 4MTPPC initiator. GPC traces of the obtained polymer are narrow, monomodal and are in good agreement with expected values from $[M]_{0} /[]_{0}$ data $\left(M_{n}=\right.$ 2.9 vs. $3.3 \mathrm{~kg} / \mathrm{mol})$. We also tested this initiator using an alternative monomer for polysarcosine synthesis. Synthesis of Sar-NCA requires the use of toxic and harmful chemicals (phosgene or thionyl chloride). Also, the purification, handling and storage of the moisture-sensitive NCA is challenging. To address this, Yamada introduced $N$-phenyloxycarbonyl amino acids for polypeptide synthesis, which was later adopted by Doriti $[147,148]$ for polypeptoids. Such monomers can be synthesized in high purity, good yield and stability and polymerized to welldefined polypeptides/polypeptoids.

Accordingly, we initiated Poc-Sar polymerization using 4MTPPC in PhCN at $70{ }^{\circ} \mathrm{C}$ (Figure 4). PSar homopolymers were obtained with $30-90 \%$ (unoptimized) yield. The yield of $30 \%$ was observed for low molecular weight PSar and is attributed to losses in the purification (precipitation) step. The products were analyzed with NMR spectroscopy, GPC and MALDIToF mass spectrometry.
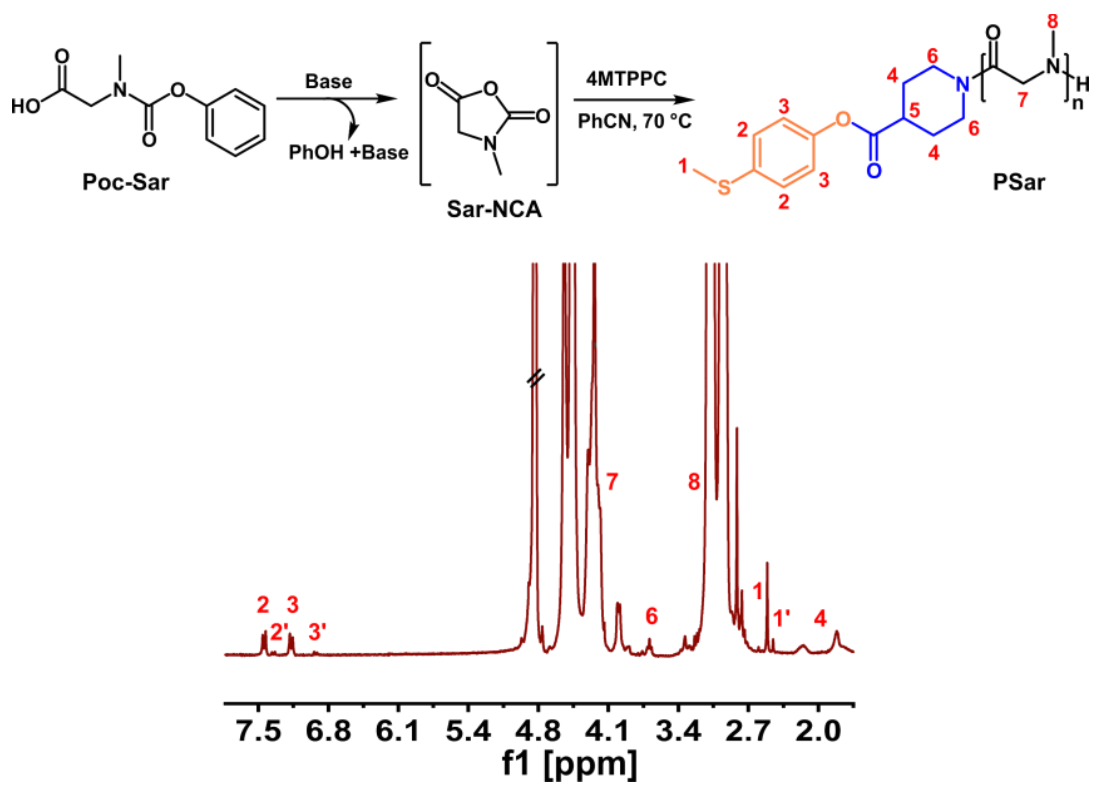

Figure 4. ${ }^{1} \mathrm{H}$ NMR spectrum $\left(300 \mathrm{MHz}, 298 \mathrm{~K}, \mathrm{D}_{2} \mathrm{O}\right)$ of the synthesized telechelic polysarcosine obtained by in situ generation of N-methylglycine NCA from an activated urethane precursor in the presence of triethylamine and 4(methylthio)phenyl piperidine-4-carboxylate initiator. 
${ }^{1} \mathrm{H}$ NMR spectra analysis shows the expected signals 2, 3 (at 7.41 and $7.17 \mathrm{ppm}$ respectively) and 1 (at $2.56 \mathrm{ppm}$ ) attributed to phenyl ring and methyl moieties of the 4MTPPC initiator. Additionally, the much smaller signals 2' (at $7.32 \mathrm{ppm}$ ), 3' (at $6.94 \mathrm{ppm}$ ) and 1' (at $2.48 \mathrm{ppm}$ ) are attributed to 4MTP, presumably formed during polymer work-up and storage (at $8.0^{\circ} \mathrm{C}$ ) (Figure 4). The GPC traces show a clear and controlled increase of the molar masses with

a)

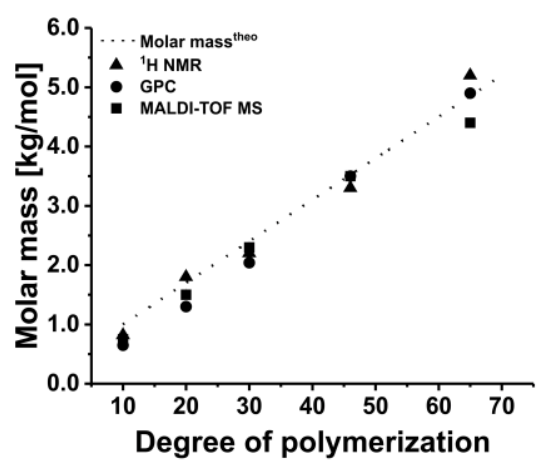

b)

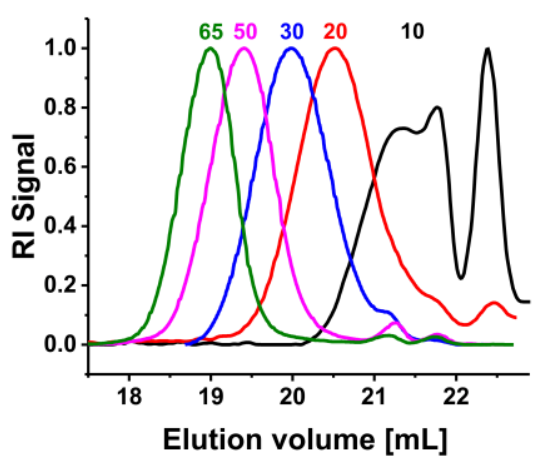

c)

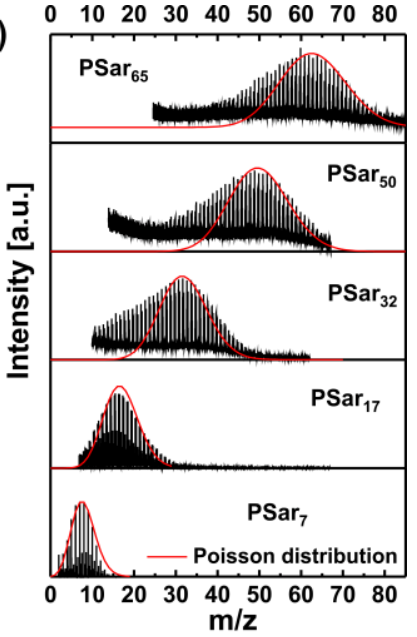

d)
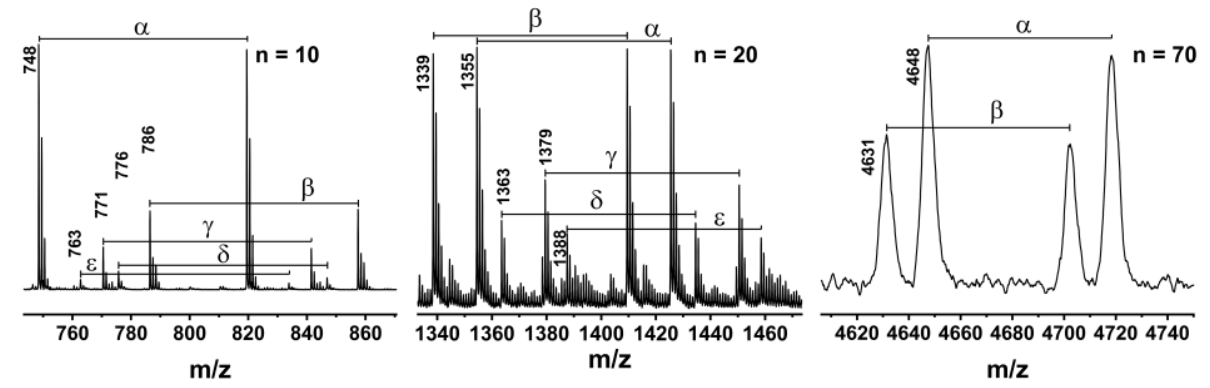

4620464046604680470047204740

$\mathrm{m} / \mathbf{z}$
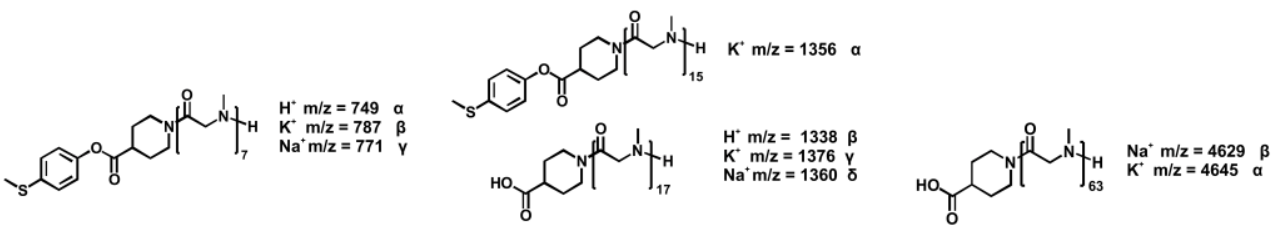

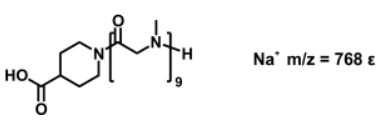

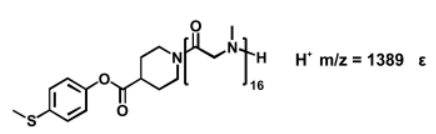

Figure 5. Overview on the characterization of 4MTPPC functionalized polymers. a) Correlation of experimentally determined and theoretical values of molar masses of polymers with different [M]//I]J. b) GPC traces of the 4MTPPC-functionalised polysarcosines with different [M]o/[I]o. c) MALDI-ToF spectra of the resulting polysarcosines and calculated Poisson distribution. The disperse distributions are overlaid with the respective Poisson distributions (red curve). d) Zoom into maximum of the molar mass distribution of the $[\mathrm{M}] \mathrm{J} /[\mathrm{I}] \mathrm{J}=10,20$ and 70 and assignment of chemical structures to respective $\mathrm{m} / \mathrm{z}$ ratios.

increasing $[\mathrm{M}]_{0} /[\mathrm{I}]_{0}$, even though the experimental molar masses tended to be somewhat smaller than expected (Figure 5a). They also show that the resulting polymers are essentially monomodal and relatively narrowly distributed, resulting in low values for $Đ$ (Figure $5 b$, supporting information, Table 1 ). The elugram of PSar with $[\mathrm{M}]_{0} /[\mathrm{I}]_{0}=10$ significantly overlaps 
with the system peak and residual solvent. We also assume that the particularly low yield for PSar with DP $=10$ is due to significant loss during work-up rather than due to problems with initiation/polymerization. Optimization of this work-up for the low-molar mass PSar was outside the scope of this contribution. Importantly, successful initiation with 4MTPPC was further confirmed with MALDI-ToF mass spectrometry. MALDI-ToF mass spectrometry confirms the increase of molar mass with increasing $[\mathrm{M}]_{0} /[]_{0}$ and also the narrow molar mass distribution (Figure $5 \mathrm{c})$. In all cases, the mass differences $(\Delta \mathrm{m} / \mathrm{z})$ between individual signal distributions reflect the molar mass of the polymer repeat unit $(71.2 \mathrm{~g} / \mathrm{mol})$. In contrast to GPC, the polymer obtained from a targeted $[\mathrm{M}]_{0} /[]_{0}=10$ shows a molar mass distribution reminiscent of a Poisson distribution, as expected for a living polymerization. The main molar mass distribution corresponds to protonated polymers initiated with 4MTPPC, bearing an amine terminus. However, $M_{n}$ calculated from the main distribution ( $\alpha$ ) peak intensities is somewhat smaller than expected, with a maximum of the distribution at a degree of polymers of $7\left(\mathrm{DP}_{\max }=7\right)$. The alternative subdistribution $\beta$ and $\gamma$ can be attributed to the same polymer bearing potassium and sodium ion doping, respectively (Figure 5d). The signals attributed to PSar with a partly hydrolyzed a-end group carrying a sodium ion doping $(\varepsilon)$ are observed. Additionally, signals of low intensities $(\mathrm{m} / \mathrm{z}=776)$ can be attributed to a polymer bearing an initiator that underwent fragmentation $(\Delta \mathrm{m} / \mathrm{z}=45)$ during the MALDI ToF MS analysis with hydrogen ion doping $(\delta)$. This can be attributed to a loss of a MeS fragment from the MTP moiety. PSar with a targeted $[\mathrm{M}]_{0} /[\mathrm{l}]_{0}=20$ also shows signals attributed to protonated polymer bearing amine terminus $(\varepsilon)$ as well as their subdistribution bearing potassium ion doping ( $\alpha$ ) (Figure $5 d)$. The presence of signals that can be attributed to a hydrolyzed a-terminus is also observed with proton $(\beta)$ potassium $(\gamma)$ and sodium $(\delta)$ ion doping. Signals observed at $\mathrm{m} / \mathrm{z}=1363$ could also be attributed to fragmented 4MTPPC-functionalized polymer bearing sodium $(\delta)$ ion doping. PSar with higher $[M]_{0} /[]_{0}(n \geq 30)$ show two principal peak distributions. The attribution of the main subdistribution ( $\alpha$ ) is unfortunately not unambiguous (Figure $5 d$ ). The broad signal could be attributed to either a partially hydrolyzed $\alpha$-terminus or a fragmented 4MTPPC $\alpha$-termini bearing potassium( $\alpha$ ) and sodium ( $\beta$ ) ion doping, respectively. The obtained signals could also 
be attributed to the desired PSar with a carbamic acid terminus. However, the latter species seems to be improbable, considering that this rather unstable species have not been reported before for PSar MALDI-ToF mass spectra.

\section{Activation of the 4MTPPC-functionalised polymers and their further functionalization}

After successful polymerization of Poc-Sar with 4MTPPC, the activation (via oxidation) of the terminal MTP esters was performed. As was reported previously, the different reagents can be used for oxidation. Johnson and Jacob treated N-carbobenzoxy amino acid MTP esters of Iysine, alanine, leucine, etc., with $30 \% \mathrm{H}_{2} \mathrm{O}_{2}$ in glacial acetic acid for $12 \mathrm{~h}$ to obtain the corresponding $\mathrm{MTO}_{2} \mathrm{P}$ esters $[152,153]$. Still, these conditions were found to be more harsh than needed. Ulbricht et al. found that high molecular weight PSar $\left([\mathrm{M}]_{0} /[\mathrm{I}]_{0}=138\right)$ undergo minor oxidative degradation during treatment with $50 \mathrm{mM}(<0.3 \%) \mathrm{H}_{2} \mathrm{O}_{2}$ at $37^{\circ} \mathrm{C}$ after $30 \mathrm{~min}$ of incubation [66, 154]. Treatment with 3.0 eq. of $m$-chloroperoxybenzoic acid $(m$-CPBA) in dioxane for $4 \mathrm{~h}$ was later found also to convert MTP ester into the activated form [141]. Recently Popovic and colleagues introduced oxone as the oxidizing agent for 4MTP activation [146]. In

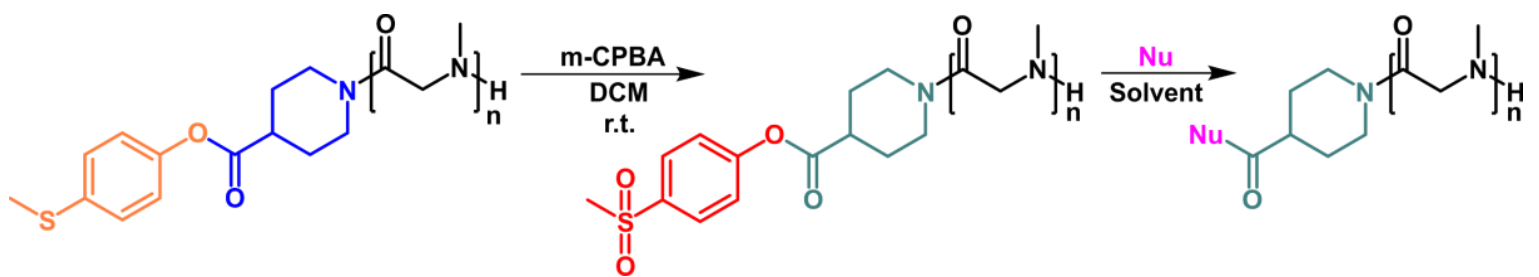

Figure 6. Schematic illustration of the activation of 4 MTPPC-functionalised polysarcosine via oxidation with 3.0 eq. of m-chloroperoxybenzoic acid and further post-polymerization modification.

a slightly different but related approach, Wu et al. reported a very interesting PPM of thiocarbamate derivatives of poly(2-oxazoline)s, which were also oxidized using $m$-CPBA to make them amendable for nucleophilic substitution [155]. Accordingly, we chose to utilize the same strategy to prevent polymer degradation and confirmed that the sulfone is generated under mild conditions with 3.0 eq. m-CPBA (Figure 6). 
${ }^{1} \mathrm{H}$ NMR spectra of the activated polymer confirm the high efficiency of the oxidation. We observe a significant shift of the aromatic signals 2 and 3 (at $7.86 \mathrm{ppm}$ and $7.46 \mathrm{ppm}$, respectively) before and after oxidation (Figure 7a, red) due to an increased electronegativity of the sulfonyl group. Likewise, signal 1, attributed to the methyl group next to sulfide/sulfonyl, is shifted and overlaps with the polymer backbone after oxidation, as was verified by oxidizing the initiator 4-MTPPC as a model compound (see supporting information, Figure S4). As the

a)

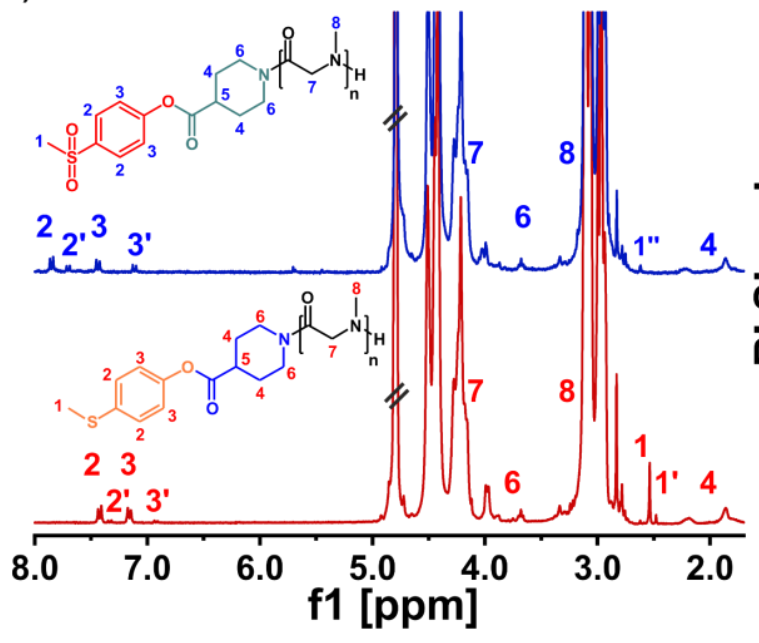

b)

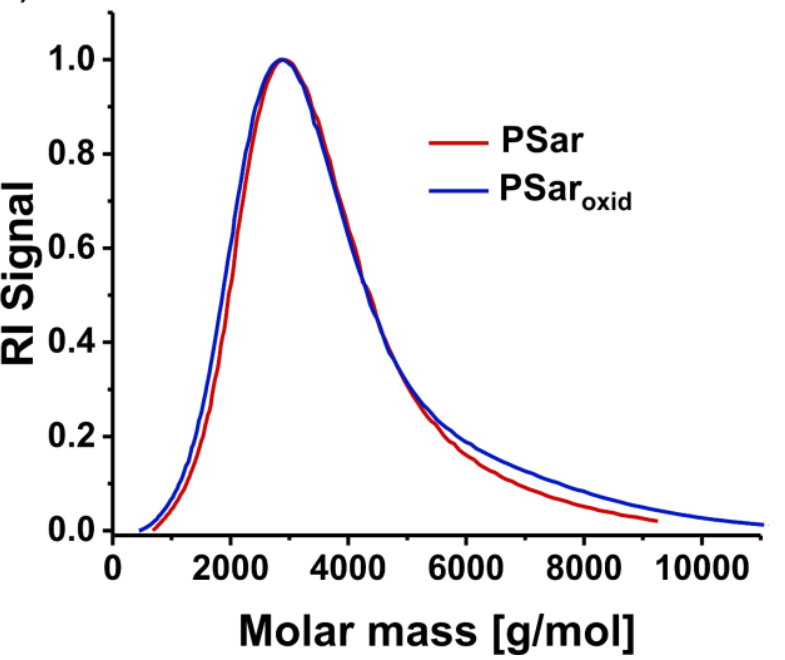

Figure 7. Characterization of the 4MTPPC-functionalized polysarcosine by a) ${ }^{1} \mathrm{H}$ NMR spectra (300 MHz, 297 $K, D_{2} \mathrm{O}$ ) and b) GPC traces before (blue) and after oxidation (red).

MTP ester is prone to hydrolysis, particularly after oxidation, we also find signals that can be attributed to a hydrolyzed terminal group. In particular, signals $2^{\prime}$ and $3^{\prime}$ (at $7.71 \mathrm{ppm}$ and 7.13 ppm, respectively) (Figure 7a, red) are attributed to 4-(methylsulfonyl)phenol, cleaved off the polymer via hydrolysis. The signal 1" (at $2.64 \mathrm{ppm}$ ) is attributed to the methyl group next to the sulfoxide (partially oxidized MTP), even though we did not observe the other signal expected for the partly oxidized phenyl ring.

GPC traces of the oxidized polymer remained monomodal, narrow and $M_{n}$ remained essentially unchanged (Figure 7b), which indicates that polymer degradation or cross-linking does not occur $[66,154]$. It should be noted, when we increased the oxidation time up to $24 \mathrm{~h}$, GPC analysis suggests polymer degradation as evidenced by a decrease of the molar mass, as well as the presence of the high molecular weight shoulder point on the interaction of macro chains, ends with each other (Supporting information Figure S5). 
After successful activation to yield oxidized polysarcosine (PSar ${ }_{\text {oxid }}$ ), we performed nucleophilic substitution with different low and higher molecular weight $\mathrm{N}$-and $\mathrm{S}$-nucleophiles. In the first experiments, PSar ${ }_{0 x i d}$ was incubated with 3.0 eq. of $\mathrm{N}$-nucleophile (benzylamine, neopentylamine and dansylcadaverine) overnight, showing a satisfying degree of functionalization (Figure 8a). ${ }^{1} \mathrm{H}$ NMR spectra of $\mathrm{PS}$ orid $_{\text {oxid }}$ treated with benzylamine in MeCN shows a new signal at $7.50 \mathrm{ppm}$ attributed to the phenyl ring of $\alpha$-benzylamine-PSar (Figure 8a). Neopentylamine modified PSar (a-neopentylamine-PSar) shows the significant shift of the signal 10' at $0.89 \mathrm{ppm}$ (attributed to free neopentylamine) to $1.04 \mathrm{ppm}$ (signal 10), confirming the successful functionalization (Figure 8b). PPM with dansylcadaverine was performed in DMSO under the same conditions following purification by precipitation from cold diethyl ether (3 times) and subsequent gel filtration ( $\mathrm{LH}-20$ with $\mathrm{MeOH}$ as eluent). The ${ }^{1} \mathrm{H}$ NMR spectra of a-dansylcadaverin-PSar shows new signals at 7.10- $8.5 \mathrm{ppm}$ (signals 12-17) attributed to aromatic moieties of dansylcadaverine (Figure 8c), while signals 9-11 were not distinguishable

a)

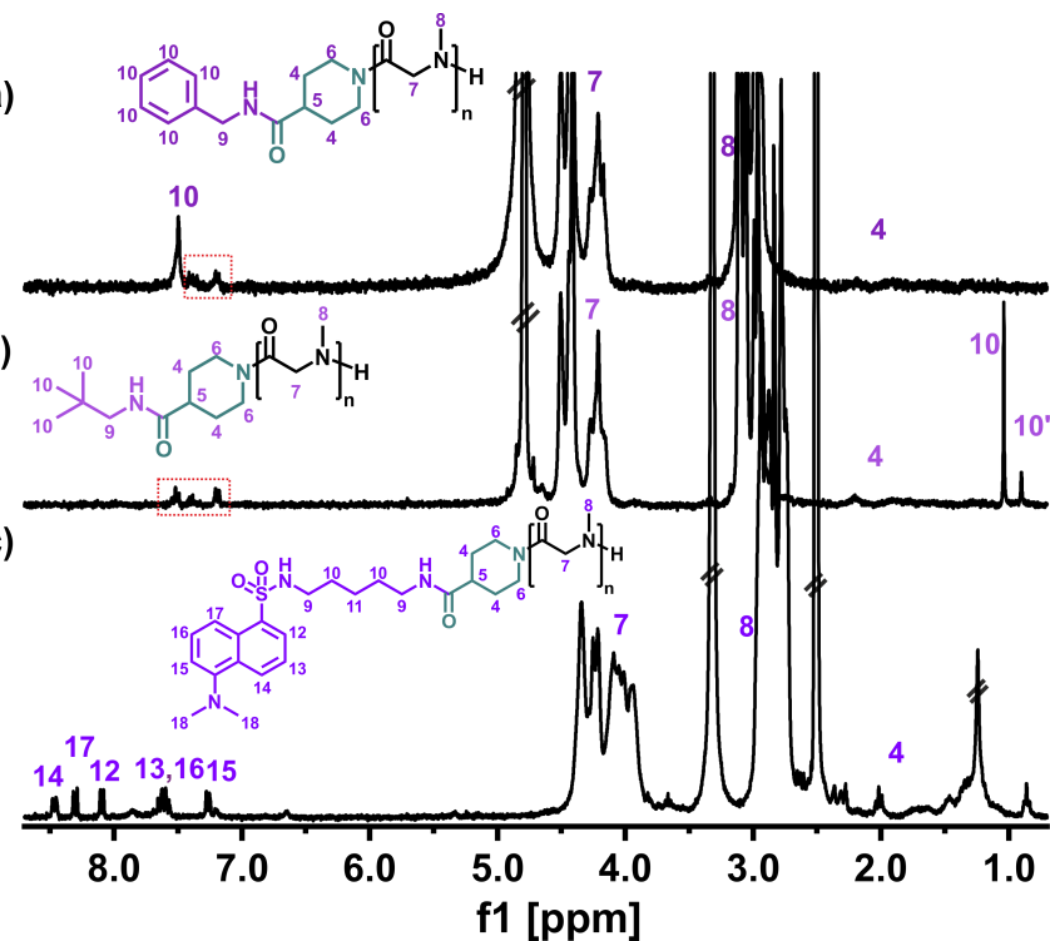

Figure 8. ${ }^{1} \mathrm{H}$ NMR (300 MHz, $297 \mathrm{~K}, \mathrm{D} 2 \mathrm{O}$ and DMSO) of modification of the activated polysarcosines with benzylamine (a), neopentylamine (b) and dansylcadaverine (c).

in the ${ }^{1} \mathrm{H}$ NMR spectra. However, we still observed signals at 7.5 - 7.8 ppm (Figure 8ab, red frame) possibly attributed to unoxidized PSar (however, the oxidative analysis shows that 
utilized conditions are enough for complete PSar oxidation) or to the presence of the residual alcohol.

MALDI-ToF MS data corroborates the functionalization of PSar with the low molecular weight nucleophiles (Figure 9). In the mass spectra of the $\alpha$-benzylamine-PSar, signals attributed to the desired product featuring an amine $\omega$-terminus and sodium ( $\mathrm{\gamma}$ ) and potassium $(\alpha)$ ion doping, respectively (Figure 9a), are observed. We also observed signals that can be attributed to oxidized PSar with proton $(\delta)$ ion doping. Signals at $\mathrm{m} / \mathrm{z}=3711$ could be attributed to the PSar starting material that underwent fragmentation and sodium $(\beta)$ ion doping. Signals suggesting the presence of PSar with a hydrolyzed MTP ester and sodium ion doping $(\varepsilon)$ were also detected.

An analysis of a-neopentylamine-PSar showed the presence of signals that can be attributed to the product bearing proton $(\omega)$, sodium $(\delta)$ and potassium $(\alpha)$ ion doping with amine $\omega$ termini (Figure 9b). However, we also observed signals that could be attributed to unoxidized PSar $(\mathrm{Y})$ or PSar ${ }_{\text {oxid }}$ bearing sodium $(\alpha)$ or potassium $(\gamma)$ ion doping with an amine $\omega$-terminus. Signals with lower intensity can be assigned to PSar with hydrolyzed 4MTPPC-a-termini bearing potassium $(\varepsilon)$ ion doping. The weaker $\delta$ distribution may be attributed to fragmented PSar chains.

Successful functionalization with dansylcadaverine is evidenced by the two most intense signals in the MS at $\mathrm{m} / \mathrm{z}=3668$ and 3683 , which can be attributed to the desired product ionized with $\mathrm{Na}^{+}(\alpha)$ and $\mathrm{K}^{+}(\beta)$, respectively, featuring an amine $\omega$-terminus. The weaker $\mathrm{y}$ and $\delta$ distributions can be attributed to residual PSar and PSar ${ }_{\text {oxid }}$ bearing potassium ion doping, respectively (Figure 9c).

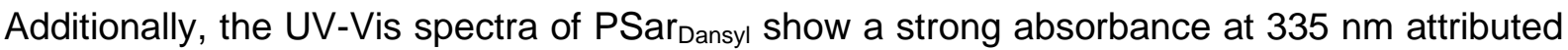
to the presence of dansylcadaverine, which was not observed in the precursor polymers (Figure S6). Quantification of the polymer conjugated dye was in excellent correlation with expected values, corroborating the potential to apply the proposed method for PPM. 
a)
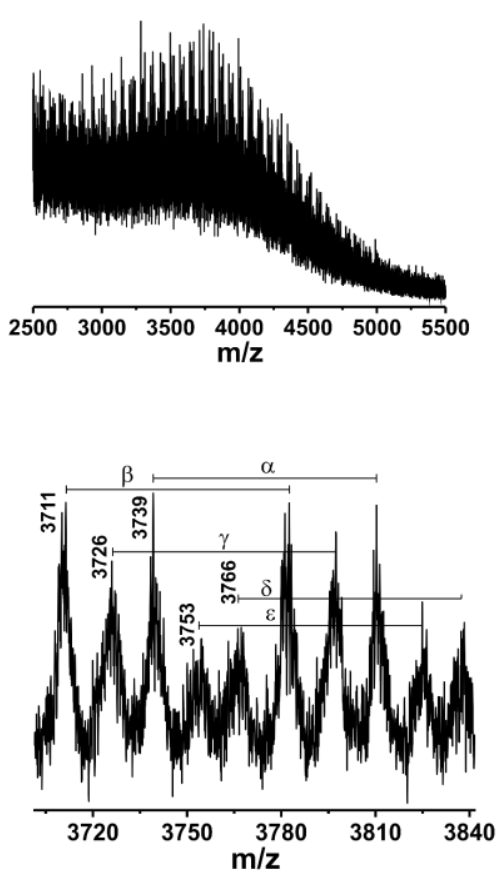

b)
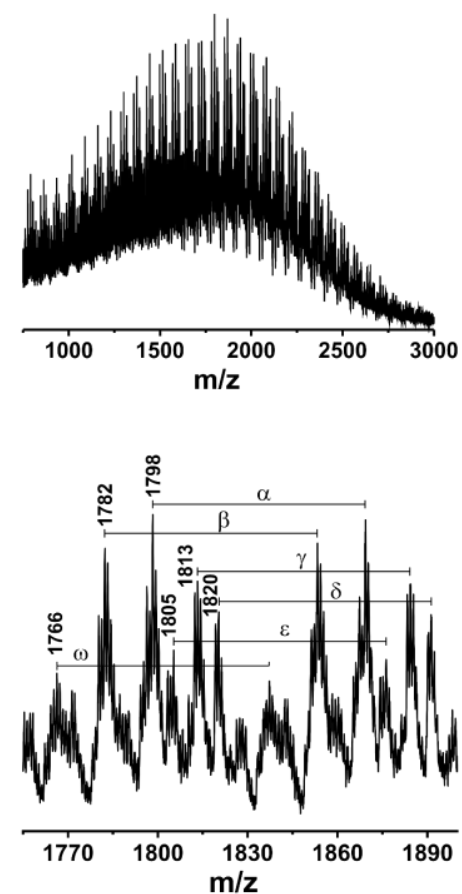

c)
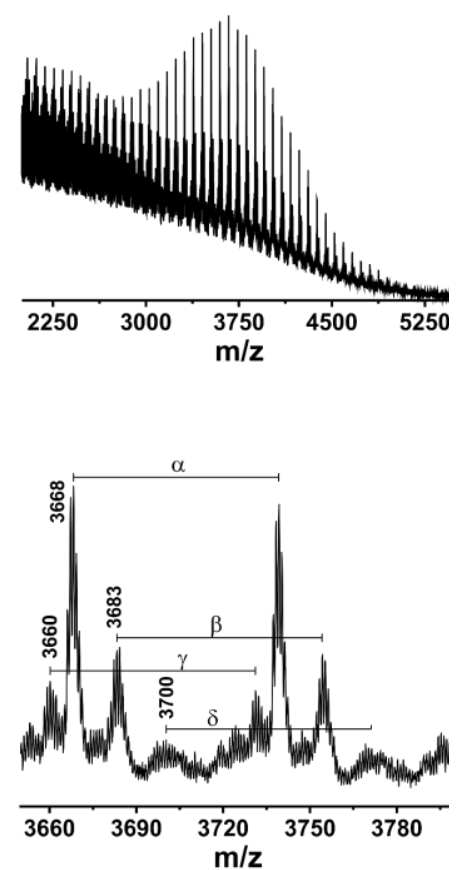<smiles>CC(C)NC(=O)N1CCC(C(=O)NCc2ccccc2)CC1</smiles>

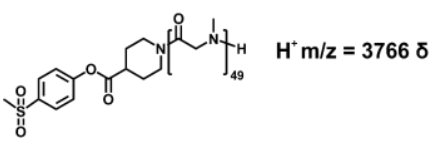

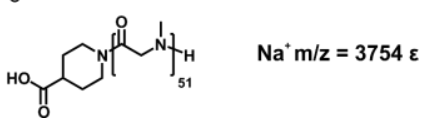

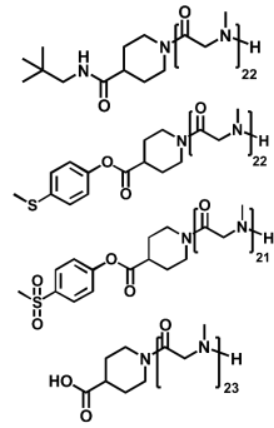

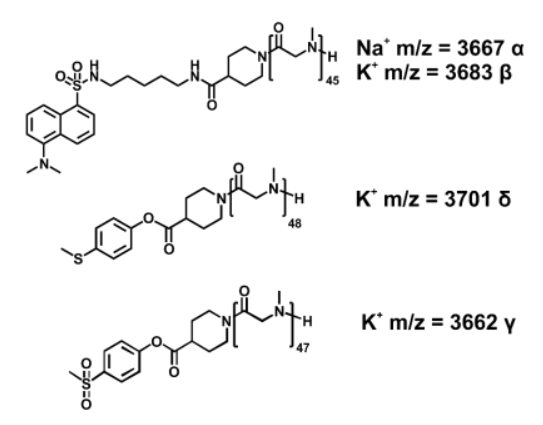

Figure 9. MALDI TOF mass spectra and structural assignment of $\mathrm{m} / \mathrm{z}$ ratio for benzylamine (a), neopentylamine (b) and dansylcadaverine (c) functionalized polysarcosines.

As a next step, we tested the more challenging conjugation with bio(macro)molecules such as peptides and proteins. The activated polymer was incubated with glutathione as a model peptide, red fluorescent protein (RFP) and bovine serum albumin (BSA) as model proteins. The conjugation was performed in phosphate buffer solution (PBS) at $\mathrm{pH}=8$ for $4-5 \mathrm{~h}$.

Glutathione (GSH) was chosen due to its antioxidant properties and the presence of two available nucleophilic groups that can, in theory, react with the activated ester group of PSar oxid. $_{\text {. }}$ As expected, GPC traces of the resulting product (PSar ${ }_{\mathrm{GHS}}$ ) after incubation demonstrate a slight but noticeable difference between the respective elution volumes. The minor difference in the apparent molar mass suggests that substitution occurs only with one available nucleophilic group (Figure 10a). The presence of a new signal at $3.80 \mathrm{ppm}$ in the ${ }^{1} \mathrm{H}$ NMR 
spectra also substantiates a successful reaction (Figure 10b). An overlay of the ${ }^{1} \mathrm{H}$ NMR spectra of PSarGHs and GHS showed that the shifting of the signals 1 and 5 depends on the used buffer solution. After incubation in the TRIS-HCl buffer, signal 1 shifted towards lower

a)

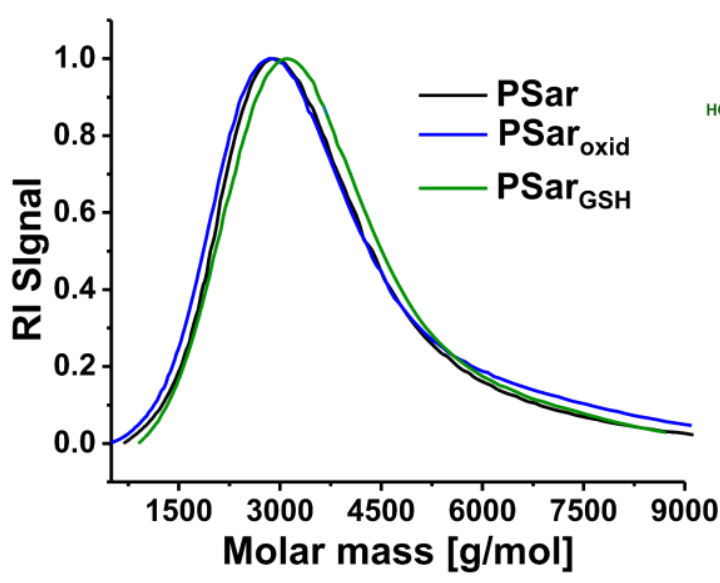

c)
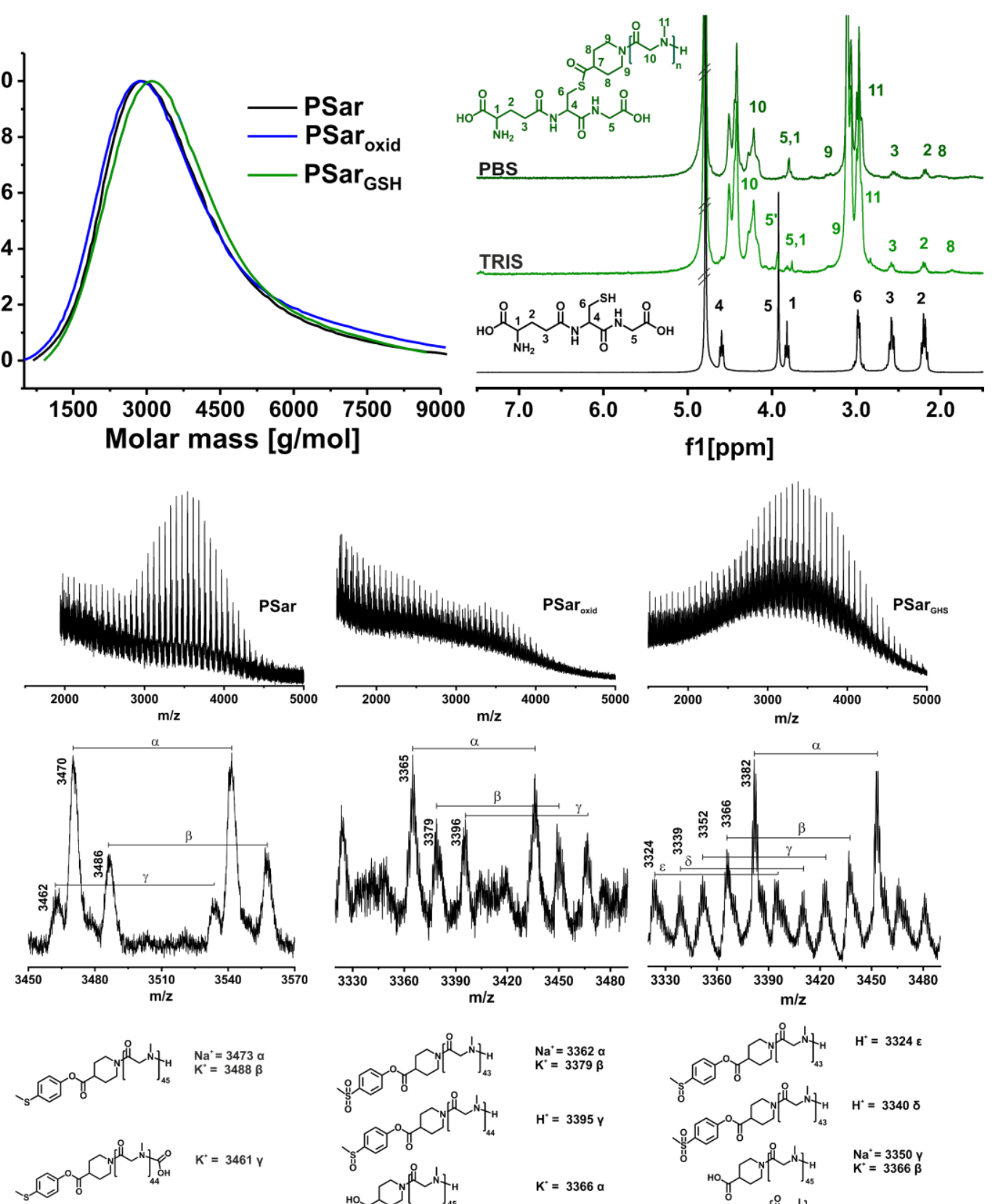
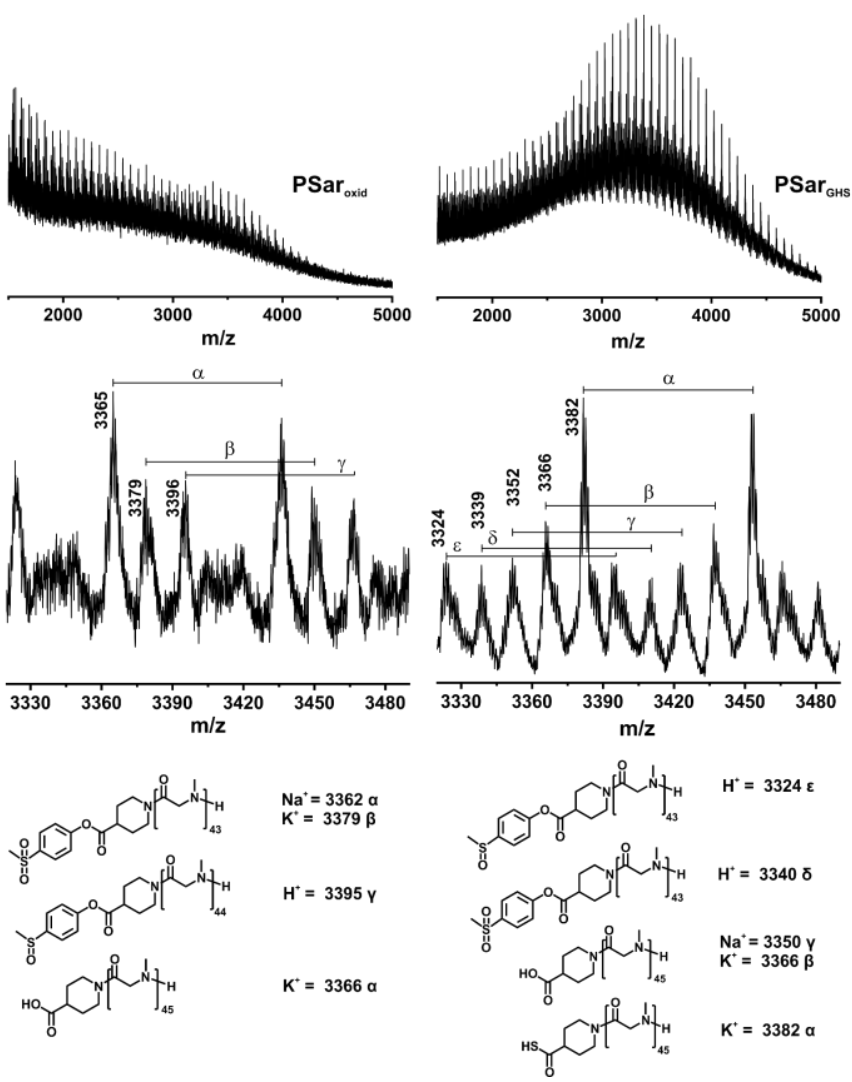

Figure 10. Functionalysation of activated polysarcosine with glutathione (GHS). a) HFIP GPC traces of the protected polysarcosine (black), activated polymer (blue) and glutathione conjugated polymer. b) ${ }^{1} \mathrm{H} N \mathrm{NMR}$ spectra (300 MHz, $297 \mathrm{~K}, \mathrm{D2O}$ ) of free glutathione (black) and glutathione conjugated polymer (green) in PBS and TRIS buffer solution respectivally. c) MALDI-ToF mass spectra and structural assignment of $\mathrm{m} / \mathrm{z}$ ratio for glutathione functionalized polysarcosines 
ppm values and a new signal at 3.80 ppm is observed, while signal 5 appears to split into two signals.

In contrast, incubation in PBS leads to a shift of the signals 1 and 5 to lower ppm values and both signals appear to overlap. Such low ppm shifting can result from the hydrogen bonds in

a)

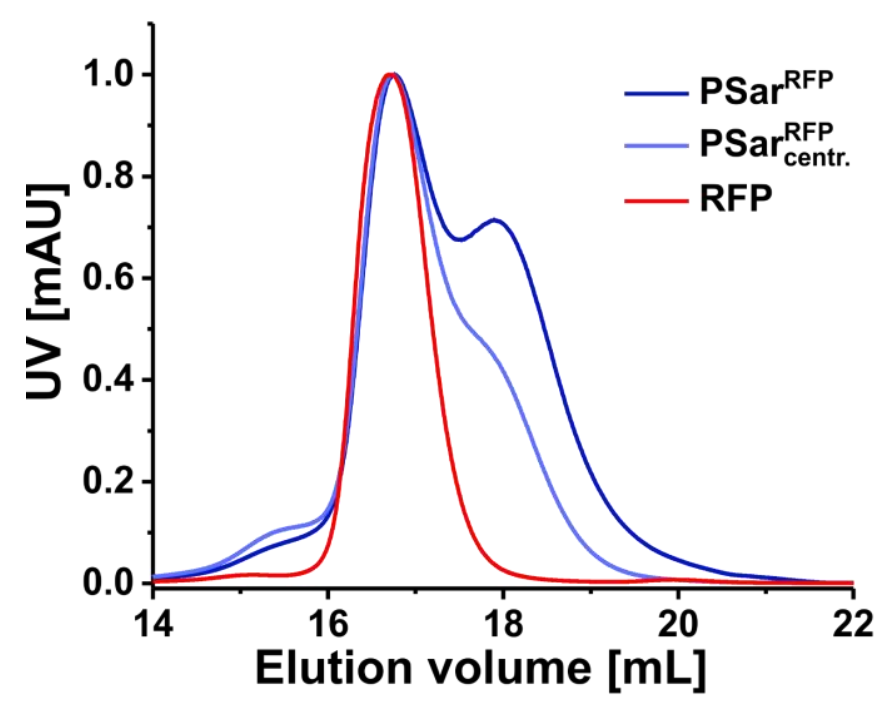

b)

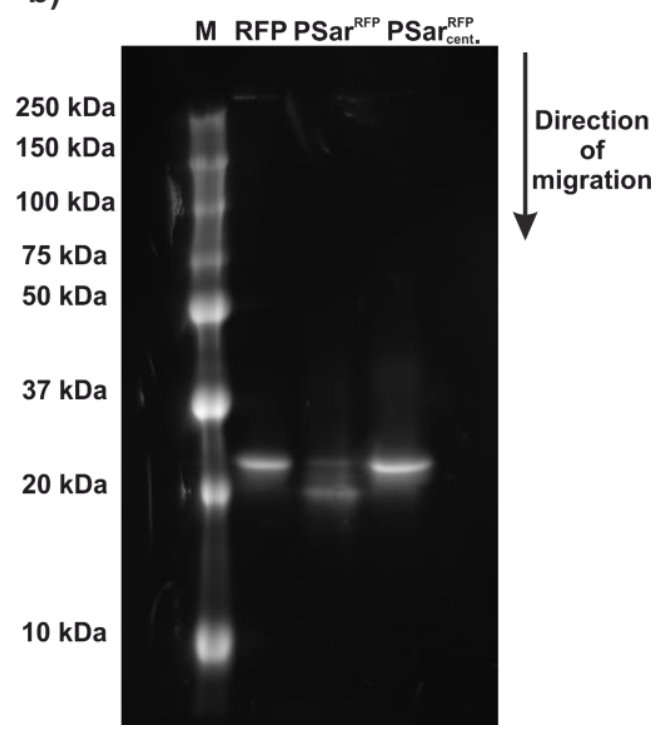

Figure 11. Conjugation of activated polymers with red fluorescent protein (RFP) a) FPLC traces of the PSar conjugated with RFP $(\lambda=280 \mathrm{~nm})$. b) Visualization of PSarRFP conjugation using polyacrylamide gel electrophoresis (PAGE). Protein molecular weight standards (M); native red fluorescent protein (RFP); reaction mixture of PSar oxid and RFP after conjugation (PSarRFP); reaction mixture of PSar oxid and RFP after conjugation and purification via centrifugation with centrifugal filter (pore size is $10 \mathrm{~kg} / \mathrm{mol})\left(P S a r\right.$ centr. $\left.{ }^{R F P}\right)$.

the water solution [156]. Unfortunately, signals 4 and 6 could not be unambiguously assigned in NMR spectra, either due to low intensity or overlap with the broad and intense signal of the polymer side chain. Important to note, the same peak shifting is observed after the reaction between oxidized 4MTPPC (4MPTO $2 \mathrm{PC})$ and GHS (Supporting information Figure S7). Signal 5 shifts completely after incubation in PBS but not TRIS-HCI, In addition, after conjugation in TRIS- $\mathrm{HCl}$, signal 6 remains largely unchanged, it essentially disappears after incubation in PBS.

The presence of side reactions such as cyclization [157] or rapid hydrolysis of resulting thioester bonds cannot be excluded. Mitamura et al. reported on the rapid hydrolysis of the thioester bond in GHS conjugated products and reports the presence of a thiocarboxylic acid and an elimination product of the thioester in mass spectra [158]. Here, MALDI-ToF mass spectrometry was performed to confirm the successful GHS conjugation. Interestingly, 
compared to PSar $_{\text {oxid, }}$, the MALDI-ToF MS of PSar $_{G H S}$ is much better resolved again gives a clear and narrow $\mathrm{m} / \mathrm{z}$ distribution. While we could not attribute signals of the fully desired GHS conjugate PSarGHS, the most intense distribution can be attributed to a thiocarboxylic acid fragment with a $\mathrm{K}^{+}(\alpha)$ ion doping (Figure 10c). We suppose that resulting PSarGHS is not ionized efficiently itself but rather degrades during MALDI-ToF analysis. However, also the presence of the signals attributed to partly oxidized $(\varepsilon)$ and oxidized $(\delta)$ PSar with amine $\omega$ termini as well as partly hydrolyzed PSar bearing sodium $(\mathrm{Y})$ and potassium $(\beta)$ ion doping is observed (Figure 10c). The presence of the PSar ${ }_{\text {oxid }}$ clearly shows that the conversion is not the complete under the chosen conditions.

Results obtained after conjugation with a red fluorescent protein (RFP) were found to be less successful. RFP was incubated with PSar oxid (with 1:5 ratio, respectively) in PBS $(\mathrm{pH}=8.0)$ for $4 \mathrm{~h}$. The resulting product (PSar RFP) was purified with a centrifugal filter and analyzed with FPLC (Figure 11a) and PAGE techniques (Figure 11b).

Judging from FPLC traces before and after conjugation (Figure 11a), only a minor fraction of RFP was conjugated with PSar, as evidenced by a minor shoulder at lower elution volumes. The PSar ${ }_{\mathrm{RFP}}$ reaction mixture is represented with two clear signals attributed to excessed PSar $_{\text {oxid }}$ and conjugated RFP (Figure 11a, dark blue). This unexpected observation could be related either to inferior conjugation degree or decreased PSar RFP hydrodynamic radius after functionalization. A noticeable decrease of the second peak and increased molecular weight shoulder after centrifugation (most molecules lower than $10.0 \mathrm{~kg} / \mathrm{mol}$ were removed) are observed (Figure 11a, blue). Side reactions could also explain the presence of the high molecular shoulder in PSar RFP traces during conjugation. PAGE analysis shows that electrophoretic patterns of RFP alone exhibit a characteristic band at ca. $25 \mathrm{~kg} / \mathrm{mol}$ while the conjugated PSar $_{\mathrm{RFP}}$ before centrifugation shows three prominent bands that could be attributed

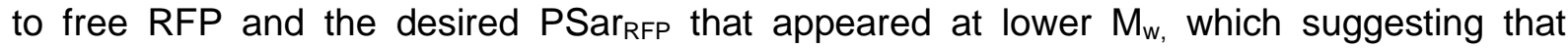

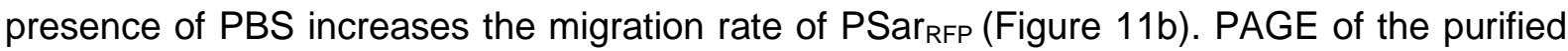
PSar $_{\text {RFP }}$ shows only one band at the same region that native RFP and the presence of minor smear at higher $\mathrm{M}_{\mathrm{w}}$ was not detected (Figure 11b). We expect that reaction conditions critically 
influence the degree of conjugation and that further improvements are needed. BSA was selected as another model protein for conjugation due to its ready availability, robust nature,

a)

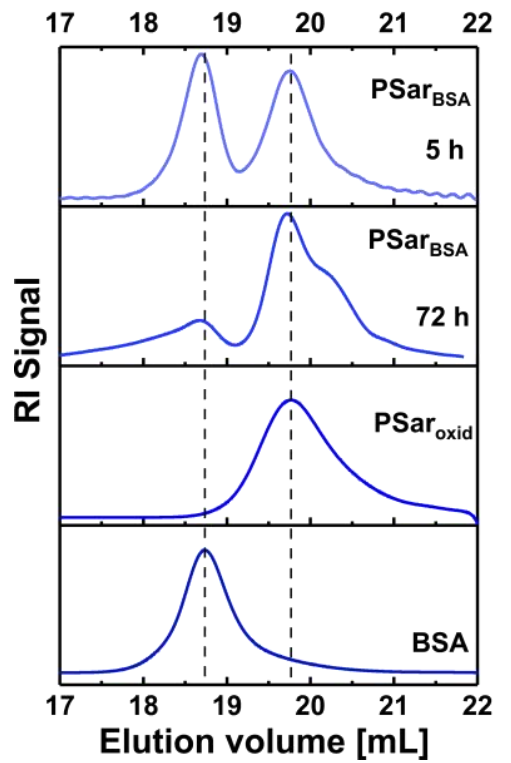

b)

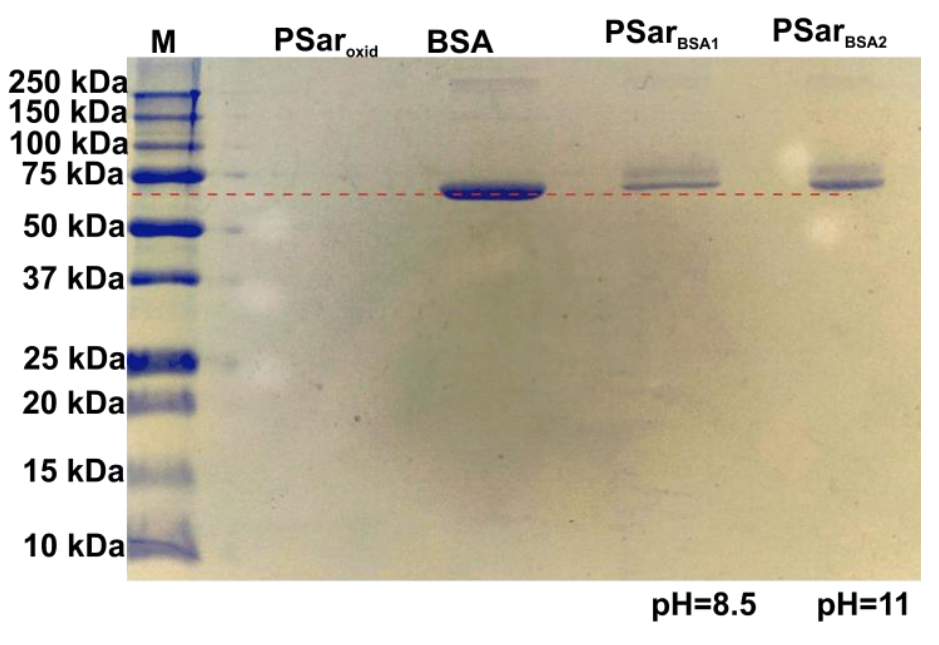

Figure 12. a) Water GPC traces of the bovine serum albumin conjugated polysarcosine. b) Visualization of bovine serum albumin conjugate using sodium dodecyl sulphate-polyacrylamide gel electrophoresis (SDSPAGE). Protein molecular weight standards (M); native oxidized polysarcosine (PSar oxid); native bovine serum albumin (BSA) bovine serum albumin conjugate performed at $\mathrm{pH}=8.5$ (PSar ${ }_{B S A 1}$ ) and bovine serum albumin conjugate performed at $\mathrm{pH}=11$ (PSarBSA2)

and the presence of an accessible free thiol at Cys-34 and 60 free amine groups available for conjugation [159-161]. The conjugation method uses a large excess of PSar $_{\text {oxid }}\left(\mathrm{M}_{\mathrm{w}}=3.5\right.$ $\mathrm{kg} / \mathrm{mol}$ ). The experiment was carried out for $5 \mathrm{~h}$ and $72 \mathrm{~h}$ in $\mathrm{PBS}$ at $\mathrm{pH}=8.0$. Subsequently, the reaction mixture was dialyzed against water for $4 \mathrm{~h}$ to remove unreacted polymer before lyophilization. GPC analysis shows a minor shift after $5 \mathrm{~h}$ and a significant tailing at higher molar mass after $72 \mathrm{~h}$ (Figure 12a). The negligible molar mass difference between PSar ${ }_{\mathrm{BSA}}$ and native BSA suggests that the conjugation via the amine group is avoided under these $\mathrm{pH}$ conditions, and only cysteine group is available for interaction. PSar ${ }_{B S A}$ incubated for $72 \mathrm{~h}$ shows higher molecular weight tailing compared with native BSA and, also, presence of low

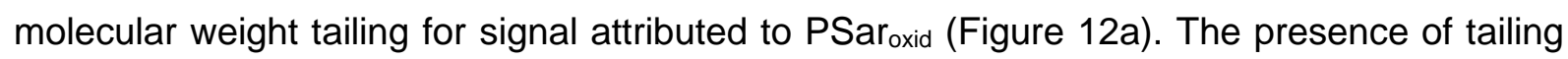
points that increased incubation time leads to increased side reactions with PSar oxid like chain coupling or degradation and increases the degree of conjugation (Figure 12a). The SDS-PAGE

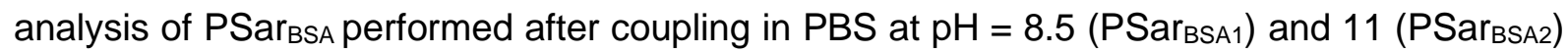


demonstrate a successful mere successful result. A small but distinct increase in molar mass was found between BSA and its corresponding conjugates (PSar ${ }_{\mathrm{BSA}}$ and PSar $\mathrm{BSA}_{2}$ ), respectively. The average molar mass was estimated to be ca. $75-80 \mathrm{~kg} / \mathrm{mol}$ (supporting information Figure SI). Our results suggest that the degree of conjugation depends on the $\mathrm{pH}$ of the reaction media (Figure 12), which is well known for the reaction of activated carboxylic acids. The difference in band intensity points that significant excess of unreacted PSar is present even after $24 \mathrm{~h}$ of dialysis (membrane pore size is $10 \mathrm{kDA}$ ).

\section{Conclusions}

This study describes the first synthesis of a functional and activatable initiator for the living ring-opening polymerization of N-carboxyanhydrides. Well-defined functionalized polysarcosines bearing this initiator can be activated via oxidation (using m-CPBA) and utilized for post-polymerization modification with different $-\mathrm{SH}$ and $-\mathrm{NH}_{2}$ nucleophiles of low and high molecular weight nucleophiles, including bovine serum albumin as a model protein. Successful functionalization was demonstrated by NMR spectroscopy, GPC, FPLC, SDS-PAGE and MALDI-ToF spectrometry. Even though there are limitations due to occurring hydrolysis of the functionalized group during storage and imperfect conjugation, we believe that the introduced method is an exciting tool for the post-polymerization bioconjugation of polypeptides and polypeptoids and could also be extended to other classes of polymers. 


\section{Reference}

[1] A. Kakkar, G. Traverso, O.C. Farokhzad, R. Weissleder, R. Langer, Evolution of macromolecular complexity in drug delivery systems, Nat.Rew.Chem. 1(8) (2017) 1-17.

[2] O. Sedlacek, R. Hoogenboom, Drug Delivery Systems Based on Poly(2-oxazoline)s and Poly(2-oxazine)s, Adv.Ther. 3(1) (2020) 1900168.

[3] W. Chen, S. Zhou, L. Ge, W. Wu, X. Jiang, Translatable High Drug Loading Drug Delivery Systems Based on Biocompatible Polymer Nanocarriers, Biomacromolecules 19(6) (2018) 1732-1745.

[4] Z. Yang, D. Gao, Z. Cao, C. Zhang, D. Cheng, J. Liu, X. Shuai, Drug and gene co-delivery systems for cancer treatment, Biomater. Sci. 3(7) (2015) 1035-1049.

[5] N. Nishiyama, K. Kataoka, Current state, achievements, and future prospects of polymeric micelles as nanocarriers for drug and gene delivery, Pharmacol. Ther. 112(3) (2006) 630-648. [6] S. Datta, A.r. Jutková, P. Šrámková, L. Lenkavská, V. Huntošová, D.a. Chorvát, P. Miškovský, D. Jancura, J. Kronek, Unravelling the Excellent Chemical Stability and Bioavailability of Solvent Responsive Curcumin-Loaded 2-Ethyl-2-oxazoline-grad-2-(4dodecyloxyphenyl)-2-oxazoline Copolymer Nanoparticles for Drug Delivery, Biomacromolecules 19(7) (2018) 2459-2471.

[7] O. Koshkina, T. Lang, R. Thiermann, D. Docter, R.H. Stauber, C. Secker, H. Schlaad, S. Weidner, B. Mohr, M. Maskos, Temperature-Triggered Protein Adsorption on Polymer-Coated Nanoparticles in Serum, Langmuir 31(32) (2015) 8873-8881.

[8] A. Zinger, L. Koren, O. Adir, M. Poley, M. Alyan, Z. Yaari, N. Noor, N. Krinsky, A. Simon, $\mathrm{H}$. Gibori, Collagenase Nanoparticles Enhance the Penetration of Drugs into Pancreatic Tumors, ACS Nano 13(10) (2019) 11008-11021.

[9] S. Grabbe, K. Landfester, D. Schuppan, M. Barz, R. Zentel, Nanoparticles and the immune system: challenges and opportunities, Nanomedicine (Lond.) 11(20) (2016) 2621-2624.

[10] S.S. Nogueira, A. Schlegel, K. Maxeiner, B. Weber, M. Barz, M.A. Schroer, C.E. Blanchet, D.I. Svergun, S. Ramishetti, D. Peer, Polysarcosine-Functionalized Lipid Nanoparticles for Therapeutic mRNA Delivery, ACS Appl. Nano Mater. 3(11) (2020) 10634-10645.

[11] H. Unterweger, R. Tietze, C. Janko, J. Zaloga, S. Lyer, S. Dürr, N. Taccardi, O.-M. Goudouri, A. Hoppe, D. Eberbeck, D.W. Schoubert, A.R. Boccaccini, C. Alexiou, Development and characterization of magnetic iron oxide nanoparticles with a cisplatin-bearing polymer coating for targeted drug delivery, Int. J. Nanomed. 9 (2014) 3659.

[12] V. Marzaioli, J.A. Aguilar-Pimentel, I. Weichenmeier, G. Luxenhofer, M. Wiemann, R. Landsiedel, W. Wohlleben, S. Eiden, M. Mempel, H. Behrendt, Surface modifications of silica nanoparticles are crucial for their inert versus proinflammatory and immunomodulatory properties, Int. J. Nanomed. 9 (2014) 2815.

[13] A. Schulz, A. Stocco, A. Bethry, J.P. Lavigne, J. Coudane, B. Nottelet, Direct Photomodification of Polymer Surfaces: Unleashing the Potential of Aryl-Azide Copolymers, Adv. Funct. Mater. 28(30) (2018) 1800976.

[14] F. Siedenbiedel, J.C. Tiller, Antimicrobial Polymers in Solution and on Surfaces: Overview and Functional Principles, Polymers 4(1) (2012) 46-71.

[15] S. Li, S. Dong, W. Xu, S. Tu, L. Yan, C. Zhao, J. Ding, X. Chen, Antibacterial Hydrogels, Adv. Sci. 5(5) (2018) 1700527.

[16] A. Alzagameem, S.E. Klein, M. Bergs, X.T. Do, I. Korte, S. Dohlen, C. Hüwe, J. Kreyenschmidt, B. Kamm, M. Larkins, M. Schulze, Antimicrobial Activity of Lignin and LigninDerived Cellulose and Chitosan Composites against Selected Pathogenic and Spoilage Microorganisms, Polymers 11(4) (2019) 670.

[17] A. Jain, L.S. Duvvuri, S. Farah, N. Beyth, A.J. Domb, W. Khan, Antimicrobial Polymers, Adv. Healthc. Mater. 3(12) (2014) 1969-1985.

[18] J. Yoo, A. Birke, J. Kim, Y. Jang, S.Y. Song, S. Ryu, B.-S. Kim, B.-G. Kim, M. Barz, K. Char, Cooperative Catechol-Functionalized Polypept(o)ide Brushes and Ag Nanoparticles for Combination of Protein Resistance and Antimicrobial Activity on Metal Oxide Surfaces, Biomacromolecules 19(5) (2018) 1602-1613. 
[19] D. Wang, G. Tong, R. Dong, Y. Zhou, J. Shen, X. Zhu, Self-assembly of supramolecularly engineered polymers and their biomedical applications, Chem. Comm. 50(81) (2014) 1199412017.

[20] Y. Zhou, W. Huang, J. Liu, X. Zhu, D. Yan, Self-Assembly of Hyperbranched Polymers and Its Biomedical Applications, Adv. Mater. 22(41) (2010) 4567-4590.

[21] Z.-X. Zhang, X. Liu, F.J. Xu, X.J. Loh, E.-T. Kang, K.-G. Neoh, J. Li, Pseudo-block copolymer based on star-shaped poly( $\mathrm{N}$-isopropylacrylamide) with a $\beta$-cyclodextrin core and guest-bearing PEG: controlling thermoresponsivity through supramolecular self-assembly, Macromolecules 41(16) (2008) 5967-5970.

[22] I.W. Hamley, PEG - Peptide Conjugates, Biomacromolecules 15(5) (2014) 1543-1559.

[23] A. Birke, J. Ling, M. Barz, Polysarcosine-containing copolymers: Synthesis, characterization, self-assembly, and applications, Prog. Polym. Sci. 81 (2018) 163-208.

[24] S.H. Petrosko, R. Johnson, H. White, C.A. Mirkin, Nanoreactors: Small Spaces, Big Implications in Chemistry, J. Am. Chem. Soc. 138(24) (2016) 7443-7445.

[25] K.T. Kim, S.A. Meeuwissen, R.J. Nolte, J.C. van Hest, Smart nanocontainers and nanoreactors, Nanoscale 2(6) (2010) 844-858.

[26] J.-H. Kim, K. Park, H.Y. Nam, S. Lee, K. Kim, I.C. Kwon, Polymers for bioimaging, Prog. Polym. Sci. 32(8-9) (2007) 1031-1053.

[27] S. Krishnan, C.J. Weinman, C.K. Ober, Advances in polymers for anti-biofouling surfaces, J. Mater. Chem. 18(29) (2008) 3405-3413.

[28] W.K. Cho, S.M. Kang, J.K. Lee, Non-biofouling polymeric thin films on solid substrates, J. Nanosci. Nanotechnol. 14(2) (2014) 1231-1252.

[29] Z. Zhang, V.E. Wagner, Antimicrobial coatings and modifications on medical devices, 1 ed., Springer, Cham, 2017.

[30] S. Cichosz, A. Masek, M. Zaborski, Polymer-based sensors: A review, Polym. Test. 67 (2018) 342-348.

[31] E. Schoolaert, R. Hoogenboom, K. De Clerck, Colorimetric Nanofibers as Optical Sensors, Adv. Funct. Mater. 27(38) (2017) 1702646.

[32] B. Guo, P.X. Ma, Conducting Polymers for Tissue Engineering, Biomacromolecules 19(6) (2018) 1764-1782.

[33] J. Malda, J. Visser, F.P. Melchels, T. Jüngst, W.E. Hennink, W.J. Dhert, J. Groll, D.W. Hutmacher, 25th Anniversary Article: Engineering Hydrogels for Biofabrication, Adv. Mater. 25(36) (2013) 5011-5028.

[34] R. Censi, W. Schuurman, J. Malda, G. Di Dato, P.E. Burgisser, W.J. Dhert, C.F. Van Nostrum, P. Di Martino, T. Vermonden, W.E. Hennink, A Printable Photopolymerizable Thermosensitive $\mathrm{p}$ (HPMAm-lactate)-PEG Hydrogel for Tissue Engineering, Adv. Funct. Mater. 21(10) (2011) 1833-1842.

[35] V.A. Ganesh, A. Baji, S. Ramakrishna, Smart functional polymers-a new route towards creating a sustainable environment, RSC Adv. 4(95) (2014) 53352-53364.

[36] M.A. Gauthier, M.I. Gibson, H.A. Klok, Synthesis of Functional Polymers by PostPolymerization Modification, Angew. Chem. Int. Ed. 48(1) (2009) 48-58.

[37] H. Palza, P.A. Zapata, C. Angulo-Pineda, Electroactive Smart Polymers for Biomedical Applications, Materials 12(2) (2019) 277.

[38] J.M. Harris, Introduction to Biotechnical and Biomedical Applications of Poly(Ethylene glycol), in: J.M. Harris (Ed.), Poly(Ethylene Glycol) Chemistry. Topics in Applied Chemistry, Springer US, Boston, MA, 1992, pp. 1-14.

[39] J.W. Johnson, Cosmetic Ingredient Review Expert Panel. Final report on the safety assessment of PEG-25 propylene glycol stearate, PEG-75 propylene glycol stearate, PEG120 propylene glycol stearate, PEG-10 propylene glycol, PEG-8 propylene glycol cocoate, and PEG-55 propylene glycol oleate, Int. J. Toxicol. 20 (2001) 13-26.

[40] K. Knop, R. Hoogenboom, D. Fischer, U.S. Schubert, Poly(ethylene glycol) in Drug Delivery: Pros and Cons as Well as Potential Alternatives, Angew. Chem. Int. Ed. 49(36) (2010) 6288-6308.

[41] Y. Qin, Y. Zhu, X. Luo, S. Liang, J. Wang, L. Zhang, End group modification of polyethylene glycol (PEG): A novel method to mitigate the supercooling of PEG as phase change material, Int. J. Energy Res. 43(2) (2019) 1000-1011. 
[42] Y. Inada, K. Takahashi, T. Yoshimoto, A. Ajima, A. Matsushima, Y. Saito, Application of polyethylene glycol-modified enzymes in biotechnological processes: organic solvent-soluble enzymes, Trends Biotechnol. 4(7) (1986) 190-194.

[43] U. Raviv, J. Frey, R. Sak, P. Laurat, R. Tadmor, J. Klein, Properties and Interactions of Physigrafted End-Functionalized Poly(ethylene glycol) Layers, Langmuir 18(20) (2002) 74827495.

[44] R.P. Garay, R. El-Gewely, J.K. Armstrong, G. Garratty, P. Richette, Antibodies against polyethylene glycol in healthy subjects and in patients treated with PEG-conjugated agents, Expert Opinion on Drug Delivery 9(11) (2012) 1319-1323.

[45] A.W. Richter, E. Åkerblom, Antibodies against polyethylene glycol produced in animals by immunization with monomethoxy polyethylene glycol modified proteins, Int. Arch. Allergy Immunol. 70(2) (1983) 124-131.

[46] J.K. Armstrong, G. Hempel, S. Koling, L.S. Chan, T. Fisher, H.J. Meiselman, G. Garratty, Antibody against poly(ethylene glycol) adversely affects PEG-asparaginase therapy in acute lymphoblastic leukemia patients, Cancer 110(1) (2007) 103-111.

[47] M.A. Becker, H.S. Baraf, R.A. Yood, A. Dillon, J. Vázquez-Mellado, F.D. Ottery, D. Khanna, J.S. Sundy, Long-term safety of pegloticase in chronic gout refractory to conventional treatment, Ann. Rheum. Dis. 72(9) (2013) 1469-1474.

[48] J. Scheirs, S.W. Bigger, O. Delatycki, Characterizing the solid-state thermal oxidation of poly(ethylene oxide) powder, Polymer 32(11) (1991) 2014-2019.

[49] S. Morlat, J.-L. Gardette, Phototransformation of water-soluble polymers. I: photo-and thermooxidation of poly(ethylene oxide) in solid state, Polymer 42(14) (2001) 6071-6079.

[50] C.A. Stone Jr, Y. Liu, M.V. Relling, M.S. Krantz, A.L. Pratt, A. Abreo, J.A. Hemler, E.J. Phillips, Immediate Hypersensitivity to Polyethylene Glycols and Polysorbates: More Common Than We Have Recognized, J. Allergy Clin. Immunol. 7(5) (2019) 1533-1540. e8.

[51] E. Wenande, L. Garvey, Immediate-type hypersensitivity to polyethylene glycols: a review, Clin. Exp. Allergy 46(7) (2016) 907-922.

[52] C. Conover, L. Lejeune, R. Linberg, K. Shum, R.G. Shorr, Transitional Vacuole Formation Following a Bolus Infusion of PEG-Hemoglobin in the Rat, Artif. Cells Nanomed. Biotechnol. 24(6) (1996) 599-611.

[53] D.G. Rudmann, J.T. Alston, J.C. Hanson, S. Heidel, High Molecular Weight Polyethylene Glycol Cellular Distribution and PEG-associated Cytoplasmic Vacuolation is Molecular Weight Dependent and Does Not Require Conjugation to Proteins, Toxicol. Pathol 41(7) (2013) 970983.

[54] https://www.fda.gov/media/104091/download. (Accessed 09.01. 2021).

[55] F. Zhang, M.-r. Liu, H.-t. Wan, Discussion about Several Potential Drawbacks of PEGylated Therapeutic Proteins, Biol. Pharm. Bull. (2014) b13-00661.

[56] N.J. Ganson, T.J. Povsic, B.A. Sullenger, J.H. Alexander, S.L. Zelenkofske, J.M. Sailstad, C.P. Rusconi, M.S. Hershfield, Pre-existing anti-polyethylene glycol antibody linked to firstexposure allergic reactions to pegnivacogin, a PEGylated RNA aptamer, J. Allergy Clin. Immunol. 137(5) (2016) 1610-1613. e7.

[57] N.E. Elsadek, E. Hondo, T. Shimizu, H. Takata, A.S. Abu Lila, S.E. Emam, H. Ando, Y. Ishima, T. Ishida, Impact of Pre-Existing or Induced Anti-PEG IgM on the Pharmacokinetics of Peginterferon Alfa-2a (Pegasys) in Mice, Molecular Pharmaceutics 17(8) (2020) 2964-2970.

[58] I. Hamad, A. Hunter, J. Szebeni, S.M. Moghimi, Poly(ethylene glycol)s generate complement activation products in human serum through increased alternative pathway turnover and a MASP-2-dependent process, Mol. Immunol. 46(2) (2008) 225-232.

[59] X.-D. Zhang, X.S. Di Wu, P.-X. Liu, N. Yang, B. Zhao, H. Zhang, Y.-M. Sun, L.-A. Zhang, F.-Y. Fan, Size-dependent in vivo toxicity of PEG-coated gold nanoparticles, Int. J. Nanomed. 6 (2011) 2071.

[60] L. Zhao, J. Kong, N. Krasteva, D. Wang, Deficit in the epidermal barrier induces toxicity and translocation of PEG modified graphene oxide in nematodes, Toxicol. Res. 7(6) (2018) 1061-1070.

[61] L.H. Garvey, S. Nasser, Allergic reactions to the first COVID-19 vaccine: is polyethylene glycol (PEG) the culprit?, Br. J. Anaesth. (2020). 
[62] M.C. Castells, E.J. Phillips, Maintaining safety with SARS-CoV-2 vaccines, N. Engl. J. Med. 384(7) (2021) 643-649.

[63] P.J. Turner, I.J. Ansotegui, D.E. Campbell, V. Cardona, M. Ebisawa, E.-G. Yehia, S. Fineman, M. Geller, A. Gonzalez-Estrada, P.A. Greenberger, COVID-19 vaccine-associated anaphylaxis: A statement of the World Allergy Organization Anaphylaxis Committee, World Allergy Organ. J. (2021) 100517.

[64] S. Bleher, J. Buck, C. Muhl, S. Sieber, S. Barnert, D. Witzigmann, J. Huwyler, M. Barz, R. Süss, Poly(sarcosine) Surface Modification Imparts Stealth-Like Properties to Liposomes, Small 15(50) (2019) 1904716.

[65] T. Lorson, M.M. Lübtow, E. Wegener, M.S. Haider, S. Borova, D. Nahm, R. Jordan, M. Sokolski-Papkov, A.V. Kabanov, R. Luxenhofer, Poly(2-oxazoline)s based biomaterials: A comprehensive and critical update, Biomaterials 178 (2018) 204-280.

[66] J. Ulbricht, R. Jordan, R. Luxenhofer, On the biodegradability of polyethylene glycol, polypeptoids and poly(2-oxazoline)s, Biomaterials 35(17) (2014) 4848-4861.

[67] M. Barz, R. Luxenhofer, R. Zentel, M.J. Vicent, Overcoming the PEG-addiction: welldefined alternatives to PEG, from structure-property relationships to better defined therapeutics, Polym. Chem. 2(9) (2011) 1900-1918.

[68] H. Zhu, Y. Chen, F.-J. Yan, J. Chen, X.-F. Tao, J. Ling, B. Yang, Q.-J. He, Z.-W. Mao, Polysarcosine brush stabilized gold nanorods for in vivo near-infrared photothermal tumor therapy, Acta Biomater. 50 (2017) 534-545.

[69] X. Tao, C. Deng, J. Ling, PEG-Amine-Initiated Polymerization of Sarcosine $\mathrm{N}$ Thiocarboxyanhydrides Toward Novel Double-Hydrophilic PEG- $b$-Polysarcosine Diblock Copolymers, Macromol. Rapid Commun. 35(9) (2014) 875-881.

[70] Y. Deng, T. Zou, X. Tao, V. Semetey, S. Trepout, S. Marco, J. Ling, M.-H. Li, Poly( $\varepsilon-$ caprolactone)-block-polysarcosine by Ring-Opening Polymerization of Sarcosine $N$ Thiocarboxyanhydride: Synthesis and Thermoresponsive Self-Assembly, Biomacromolecules 16(10) (2015) 3265-3274.

[71] C. Hörtz, A. Birke, L. Kaps, S. Decker, E. Wächtersbach, K. Fischer, D. Schuppan, M. Barz, M. Schmidt, Cylindrical Brush Polymers with Polysarcosine Side Chains: A Novel Biocompatible Carrier for Biomedical Applications, Macromolecules 48(7) (2015) 2074-2086.

[72] Y. Hu, Y. Hou, H. Wang, H. Lu, Polysarcosine as an Alternative to PEG for Therapeutic Protein Conjugation, Bioconjugate Chem. 29(7) (2018) 2232-2238.

[73] C.W. Wu, T.J. Sanborn, K. Huang, R.N. Zuckermann, A.E. Barron, Peptoid oligomers with a-chiral, aromatic side chains: sequence requirements for the formation of stable peptoid helices, J. Am. Chem. Soc. 123(28) (2001) 6778-6784.

[74] K. Kirshenbaum, A.E. Barron, R.A. Goldsmith, P. Armand, E.K. Bradley, K.T. Truong, K.A. Dill, F.E. Cohen, R.N. Zuckermann, Sequence-specific polypeptoids: a diverse family of heteropolymers with stable secondary structure, Proc. Natl. Acad. Sci. U.S.A. 95(8) (1998) 4303-4308.

[75] K. Klinker, M. Barz, Polypept(o)ides: Hybrid Systems Based on Polypeptides and Polypeptoids, Macromol. Rapid Commun. 36(22) (2015) 1943-1957.

[76] D. Zhang, S.H. Lahasky, L. Guo, C.-U. Lee, M. Lavan, Polypeptoid Materials: Current Status and Future Perspectives, Macromolecules 45(15) (2012) 5833-5841.

[77] S.H. Lahasky, X. Hu, D. Zhang, Thermoresponsive Poly(a-peptoid)s: Tuning the Cloud Point Temperatures by Composition and Architecture, ACS Macro Lett. 1(5) (2012) 580-584.

[78] A. Li, D. Zhang, Synthesis and Characterization of Cleavable Core-Cross-Linked Micelles Based on Amphiphilic Block Copolypeptoids as Smart Drug Carriers, Biomacromolecules 17(3) (2016) 852-861.

[79] P. Heller, A. Birke, D. Huesmann, B. Weber, K. Fischer, A. Reske-Kunz, M. Bros, M. Barz, Introducing PeptoPlexes: Polylysine-block-Polysarcosine Based Polyplexes for Transfection of HEK 293T Cells ${ }^{\text {a }}$ Macromol. Biosci. 14(10) (2014) 1380-1395.

[80] B. Weber, C. Seidl, D. Schwiertz, M. Scherer, S. Bleher, R. Süss, M. Barz, PolysarcosineBased Lipids: from Lipopolypeptoid Micelles to Stealth-Like Lipids in Langmuir Blodgett Monolayers, Polymers 8(12) (2016) 427.

[81] S. Varlas, P.G. Georgiou, P. Bilalis, J.R. Jones, N. Hadjichristidis, R.K. O'Reilly, Poly(sarcosine)-Based Nano-objects with Multi-Protease Resistance by Aqueous 
Photoinitiated Polymerization-Induced Self-assembly (Photo-PISA), Biomacromolecules 19(11) (2018) 4453-4462.

[82] M. Schneider, Z. Tang, M. Richter, C. Marschelke, P. Förster, E. Wegener, I. Amin, H. Zimmermann, D. Scharnweber, H.G. Braun, Patterned Polypeptoid Brushes, Macromol. Biosci. 16(1) (2016) 75-81.

[83] K.H.A. Lau, C. Ren, T.S. Sileika, S.H. Park, I. Szleifer, P.B. Messersmith, Surface-Grafted Polysarcosine as a Peptoid Antifouling Polymer Brush, Langmuir 28(46) (2012) 16099-16107. [84] S. Cui, X. Pan, H. Gebru, X. Wang, J. Liu, J. Liu, Z. Li, K. Guo, Amphiphilic star-shaped poly(sarcosine)-block-poly( $\varepsilon$-caprolactone) diblock copolymers: one-pot synthesis, characterization, and solution properties, Journal of Materials Chemistry B 5(4) (2017) 679690.

[85] C. Fetsch, J. Gaitzsch, L. Messager, G. Battaglia, R. Luxenhofer, Self-Assembly of Amphiphilic Block Copolypeptoids-Micelles, Worms and Polymersomes, Sci. Rep. 6 (2016) 33491.

[86] E. Ostuni, R.G. Chapman, R.E. Holmlin, S. Takayama, G.M. Whitesides, A Survey of Structure- Property Relationships of Surfaces that Resist the Adsorption of Protein, Langmuir 17(18) (2001) 5605-5620.

[87] B. Weber, A. Birke, K. Fischer, M. Schmidt, M. Barz, Solution Properties of Polysarcosine: From Absolute and Relative Molar Mass Determinations to Complement Activation, Macromolecules 51(7) (2018) 2653-2661.

[88] R. Luxenhofer, C. Fetsch, A. Grossmann, Polypeptoids: A Perfect Match for Molecular Definition and Macromolecular Engineering?, J. Polym. Sci., Part A: Polym. Chem. 51(13) (2013) 2731-2752.

[89] N. Gangloff, J. Ulbricht, T. Lorson, H. Schlaad, R. Luxenhofer, Peptoids and Polypeptoids at the Frontier of Supra-and Macromolecular Engineering, Chem. Rev. 116(4) (2016) 17531802.

[90] O. Schäfer, D. Huesmann, M. Barz, Poly(S-ethylsulfonyl-L-cysteines) for Chemoselective Disulfide Formation, Macromolecules 49(21) (2016) 8146-8153.

[91] C. Fetsch, A. Grossmann, L. Holz, J.F. Nawroth, R. Luxenhofer, Polypeptoids from NSubstituted Glycine N-Carboxyanhydrides: Hydrophilic, Hydrophobic, and Amphiphilic Polymers with Poisson Distribution, Macromolecules 44(17) (2011) 6746-6758.

[92] H.R. Kricheldorf, a-aminoacid-N-carboxy-anhydrides and related heterocycles: syntheses, properties, peptide synthesis, polymerization, 1 ed., Springer Berlin, 1987.

[93] W. Zhao, Y. Gnanou, N. Hadjichristidis, Organocatalysis by hydrogen-bonding: a new approach to controlled/living polymerization of a-amino acid N-carboxyanhydrides, Polym. Chem. 6(34) (2015) 6193-6201.

[94] B.A. Chan, S. Xuan, M. Horton, D. Zhang, 1, 1, 3, 3-Tetramethylguanidine-Promoted RingOpening Polymerization of N-Butyl N-Carboxyanhydride Using Alcohol Initiators, Macromolecules 49(6) (2016) 2002-2012.

[95] S. Gradisar, E. Zagar, D. Pahovnik, Ring-Opening Polymerization of $\mathrm{N}$-carboxyanhydrides Initiated by a Hydroxyl Group, ACS Macro Lett. 6(6) (2017) 637-640.

[96] X. Zhang, S. Monge, M. In, O. Giani, J.-J. Robin, Thermo-and pH-sensitive aggregation behavior of PDEAm- $b-\mathrm{P}(\mathrm{L}$-lysine $)$ double hydrophilic block copolymers in aqueous solution, Soft Matter 9(4) (2013) 1301-1309.

[97] T. Stukenkemper, J. Jansen, C. Lavilla, A. Dias, D. Brougham, A. Heise, Polypeptides by light: photo-polymerization of $N$-carboxyanhydrides (NCA), Polym. Chem. 8(5) (2017) 828-832. [98] H. Peng, J. Ling, Y. Zhu, L. You, Z. Shen, Polymerization of a-Amino Acid NCarboxyanhydrides Catalyzed by Rare Earth Tris (borohydride) Complexes: Mechanism and Hydroxy-Endcapped Polypeptides, J. Polym. Sci., Part A: Polym. Chem. 50(15) (2012) 30163029.

[99] J. Ling, H. Peng, Z. Shen, Deprotonation Reaction of a-Amino acid N-Carboxyanhydride at 4-CH Position by Yttrium Tris[bis (trimethylsilyl)amide], J. Polym. Sci., Part A: Polym. Chem. 50(18) (2012) 3743-3749.

[100] T. Bai, J. Ling, NAM-TMS Mechanism of a-Amino Acid N-Carboxyanhydride Polymerization: A DFT Study, The Journal of Physical Chemistry A 121(23) (2017) 4588-4593. 
[101] X. Tao, M.-H. Li, J. Ling, a-Amino acid $N$-thiocarboxyanhydrides: a novel synthetic approach toward poly( $\alpha$-amino acid)s, Eur. Polym. J. 109 (2018) 26-42.

[102] X. Tao, Y. Deng, Z. Shen, J. Ling, Controlled Polymerization of N-Substituted Glycine NThiocarboxyanhydrides Initiated by Rare Earth Borohydrides toward Hydrophilic and Hydrophobic Polypeptoids, Macromolecules 47(18) (2014) 6173-6180.

[103] X. Tao, B. Zheng, T. Bai, M.-H. Li, J. Ling, Polymerization of N-Substituted Glycine NThiocarboxyanhydride through Regioselective Initiation of Cysteamine: A Direct Way toward Thiol-Capped Polypeptoids, Macromolecules 51(12) (2018) 4494-4501.

[104] K. Johann, D. Svatunek, C. Seidl, S. Rizzelli, T.A. Bauer, L. Braun, K. Koynov, H. Mikula, M. Barz, Tetrazine-and trans-cyclooctene-functionalised polypept(o)ides for fast bioorthogonal tetrazine ligation, Polym. Chem. 11(27) (2020) 4396-4407.

[105] R. Kakuchi, P. Theato, Post-polymerization modifications via active esters, Funct. Polym. Post-Polym. Modif (2013) 45-64.

[106] U.S. Gunay, B. Ozsoy, H. Durmaz, G. Hizal, U. Tunca, V-shaped Graft Copolymers via Triple Click Reactions: Diels-Alder, Copper-Catalyzed Azide-Alkyne Cycloaddition, and Nitroxide Radical Coupling, J. Polym. Sci., Part A: Polym. Chem. 51(21) (2013) 4667-4674.

[107] D.J. Hall, H.M. Van Den Berghe, A.P. Dove, Synthesis and post-polymerization modification of maleimide-containing polymers by 'thiol-ene' click and Diels-Alder chemistries, Polym. Int. 60(8) (2011) 1149-1157.

[108] S.I. Subnaik, C.E. Hobbs, Flow-facilitated ring opening metathesis polymerization (ROMP) and post-polymerization modification reactions, Polym. Chem. 10(33) (2019) 45244528.

[109] C. Barner-Kowollik, F.E. Du Prez, P. Espeel, C.J. Hawker, T. Junkers, H. Schlaad, W. Van Camp, "Clicking" Polymers or Just Efficient Linking: What is the Difference?, Angew. Chem. Int. Ed. 50(1) (2011) 60-62.

[110] R. Luxenhofer, A tutorial translation of the description of the historically first polymer drug conjugate and its in vivo evaluation, Zeitschrift für Naturforschung C 75(9-10) (2020) 303-311. [111] H. Jatzkewitz, Über den Einbau physiologisch wirksamer Substanzen in ein kollodiales Blutplasma-Ersatzmittel, (1954).

[112] H. Jatzkewitz, An ein kolloidales Blutplasma-Ersatzmittel (Polyvinylpyrrolidon) gebundenes Peptamin (Glycyl-L-leucyl-mezcalin) als neuartige Depotform für biologisch aktive primäre Amine (Mezcalin), Zeitschrift für Naturforschung B 10(1) (1955) 27-31.

[113] P. Ferruti, A. Bettelli, A. Fere, High polymers of acrylic and methacrylic esters of $\mathrm{N}$ hydroxysuccinimide as polyacrylamide and polymethacrylamide precursors, Polymer 13(10) (1972) 462-464.

[114] H.G. Batz, G. Franzmann, H. Ringsdorf, Pharmakologisch aktive Polymere, 5. Modellreaktionen zur Umsetzung von Pharmaka und Enzymen mit Monomeren und Polymeren reaktiven Estern, Die Makromolekulare Chemie: Macromolecular Chemistry and Physics 172(1) (1973) 27-47.

[115] A. Das, P. Theato, Activated Ester Containing Polymers: Opportunities and Challenges for the Design of Functional Macromolecules, Chem. Rev. 116(3) (2016) 1434-1495.

[116] H.C. Kolb, K.B. Sharpless, The growing impact of click chemistry on drug discovery, Drug Discovery Today 8(24) (2003) 1128-1137.

[117] D.J.V. van Steenis, O.R. David, G.P. van Strijdonck, J.H. van Maarseveen, J.N. Reek, Click-chemistry as an efficient synthetic tool for the preparation of novel conjugated polymers, Chemical communications (34) (2005) 4333-4335.

[118] R.A. Evans, The Rise of Azide-Alkyne 1, 3-Dipolar 'Click' Cycloaddition and its Application to Polymer Science and Surface Modification, Aust. J. Chem. 60(6) (2007) 384395.

[119] P.K. Avti, D. Maysinger, A. Kakkar, Alkyne-Azide "Click" Chemistry in Designing Nanocarriers for Applications in Biology, Molecules 18(8) (2013) 9531-9549.

[120] J. Huo, C. Lin, J. Liang, A brief minireview of poly-triazole: Alkyne and azide substrate selective, metal-catalyst expansion, React. Funct. Polym. 152 (2020) 104531.

[121] J.-F. Lutz, Z. Zarafshani, Efficient construction of therapeutics, bioconjugates, biomaterials and bioactive surfaces using azide-alkyne "click" chemistry, Adv. Drug Deliv. Rev. 60(9) (2008) 958-970. 
[122] O. Schäfer, M. Barz, Of Thiols and Disulfides: Methods for Chemoselective Formation of Asymmetric Disulfides in Synthetic Peptides and Polymers, Chem. Eur. J. 24(47) (2018) 12131-12142.

[123] W. Zhang, K. Chen, G. Chen, Thiol-based "click" chemistry for macromolecular architecture design, in: W. Zhang, K. Chen, G. Chen (Eds.), Click reactions in organic synthesis2016.

[124] B. Huang, X. Liu, L. Tan, Z. Cui, X. Yang, D. Jing, D. Zheng, Z. Li, Y. Liang, S. Zhu, "Imitative" click chemistry to form a sticking xerogel for the portable therapy of bacteria-infected wounds, Biomater. Sci. 7(12) (2019) 5383-5387.

[125] J. Zhang, Y. Chen, M.A. Brook, Facile Functionalization of PDMS Elastomer Surfaces Using Thiol-Ene Click Chemistry, Langmuir 29(40) (2013) 12432-12442.

[126] O. Schäfer, K. Klinker, L. Braun, D. Huesmann, J. Schultze, K. Koynov, M. Barz, Combining Orthogonal Reactive Groups in Block Copolymers for Functional Nanoparticle Synthesis in a Single Step, ACS Macro Lett. 6(10) (2017) 1140-1145.

[127] J.C. Lim, J.M. Gruschus, G. Kim, B.S. Berlett, N. Tjandra, R.L. Levine, A Low pKa Cysteine at the Active Site of Mouse Methionine Sulfoxide Reductase A, J. Biol. Chem. 287(30) (2012) 25596-25601.

[128] D.H. Bianchi, The paradoxical influence of the pKa on the reactivity of thiols and its biological relevance, MaRBLe 2 (2014) 222-231.

[129] B. Sun, C. Luo, H. Yu, X. Zhang, Q. Chen, W. Yang, M. Wang, Q. Kan, H. Zhang, Y. Wang, Disulfide Bond-Driven Oxidation-and Reduction-Responsive Prodrug Nanoassemblies for Cancer Therapy, Nano Lett. 18(6) (2018) 3643-3650.

[130] J.R. Winther, C. Thorpe, Quantification of thiols and disulfides, Biochim. Biophys. Acta 1840(2) (2014) 838-846.

[131] G. Ferrer-Sueta, B. Manta, H. Botti, R. Radi, M. Trujillo, A. Denicola, Factors Affecting Protein Thiol Reactivity and Specificity in Peroxide Reduction, Chem. Res. Toxicol. 24(4) (2011) 434-450.

[132] D. Sheehan, B. McDonagh, J.A. Bárcena, Redox proteomics, EXPERT REV PROTEOMIC 7(1) (2010) 1-4.

[133] R.M. Strongin, L. Hakuna, H. Peng, W. Chen, Y. Cheng, B. Wang, Thiol Reactive Probes and Chemosensors, Sensors (2012).

[134] J. Sun, H. Schlaad, Thiol-Ene Clickable Polypeptides, Macromolecules 43(10) (2010) 4445-4448.

[135] P. Ochtrop, C.P.R. Hackenberger, Recent advances of thiol-selective bioconjugation reactions, Curr. Opin. Chem. Biol. 58 (2020) 28-36.

[136] J.-S. Zheng, S. Tang, Y.-C. Huang, L. Liu, Development of New Thioester Equivalents for Protein Chemical Synthesis, Accounts of chemical research 46(11) (2013) 2475-2484.

[137] P.A. Jackson, J.C. Widen, D.A. Harki, K.M. Brummond, Covalent Modifiers: A Chemical Perspective on the Reactivity of $\alpha, \beta$-Unsaturated Carbonyls with Thiols via Hetero-Michael Addition Reactions, J. Med. Chem. 60(3) (2017) 839-885.

[138] A. Stanic, S. Uhlig, A. Solhaug, F. Rise, A.L. Wilkins, C.O. Miles, Nucleophilic Addition of Thiols to Deoxynivalenol, J. Agric. Food. Chem. 63(34) (2015) 7556-7566.

[139] D. Sticker, R. Geczy, U.O. Häfeli, J.P. Kutter, Thiol-ene Based Polymers as Versatile Materials for Microfluidic Devices for Life Sciences Applications, ACS Appl. Mater. Interfaces 12 (2020) 10080 - 10095.

[140] B.J. Johnson, P.M. Jacobs, A New Carboxy-protecting Group for Peptide Synthesis and Its Direct Conversion into an Activated Ester Suitable for Peptide Formation: 4(Methylthio)phenyl and 4-(Methylsulphonyl)phenyl Esters, Chem.Comm. (London) (2) (1968) 73b-75.

[141] B.J. Johnson, T.A. Ruettinger, N-Acylamino Acid Esters of 4-(Methylthio)phenol, J. Org. Chem. 35(1) (1970) 255-257.

[142] B.J. Johnson, D.S. Rea, The 4-(methylthio) phenyl ester for the synthesis of polypeptides of a known repeating sequence of amino acids. Synthesis of poly-(L-lysylglycyl) glycine $1-\mathrm{C}^{14}$ ethyl ester hydrobromide, Can. J. Chem. 48(16) (1970) 2509-2511.

[143] W.-Y. Chen, M.-L. Hsu, R.K. Olsen, Synthesis of a Model Depsipeptide Lactone Related to the Quinoxaline Antibiotics, J. Org. Chem. 40(21) (1975) 3110-3112. 
[144] L.M. Siemens, F.W. Rottnek, L.S. Trzupek, Selective Catalysis of Ester Aminolysis: An Approach to Peptide Active Esters, J. Org. Chem. 55(11) (1990) 3507-3511.

[145] S.-Y. Cho, B.-D. Park, S.-M. Oh, Y.-S. Lee, The electrochemical activation of amino acid 4-(methylthio)phenyl ester and its application in peptide synthesis, Bull. Korean Chem. Soc. 15(4) (1994) 324-326.

[146] S. Popovic, H. Bieräugel, R.J. Detz, A.M. Kluwer, J.A. Koole, D.E. Streefkerk, H. Hiemstra, J.H. van Maarseveen, Epimerization-Free C-Terminal Peptide Activation, Chem. Eur. J. 19(50) (2013) 16934-16937.

[147] A. Doriti, S.M. Brosnan, S.M. Weidner, H. Schlaad, Synthesis of polysarcosine from air and moisture stable $N$-phenoxycarbonyl- $N$-methylglycine assisted by tertiary amine base, Polym. Chem. 7(18) (2016) 3067-3070.

[148] S. Yamada, K. Koga, T. Endo, Useful Synthetic Method of Polypeptides with WellDefined Structure by Polymerization of Activated Urethane Derivatives of a-Amino Acids, J. Polym. Sci., Part A: Polym. Chem. 50(13) (2012) 2527-2532.

[149] F. Fuchs, Über N-carbonsäure-anhydride, Ber. Dtsch. Chem. Ges. 55(9) (1922) 29432943.

[150] Ö. Alver, C. Parlak, M. Bilge, Experimental and theoretical NMR study of 4-(1-pyrrolidinyl) piperidine, Bull. Chem. Soc. Ethiop. 25(3) (2011) 437-442.

[151] A.M. Rydzik, I.K. Leung, G.T. Kochan, M.A. McDonough, T.D. Claridge, C.J. Schofield, Oxygenase-Catalyzed Desymmetrization of $N$, N-Dialkyl-piperidine-4-carboxylic Acids, Angew. Chem. 126(41) (2014) 11105-11107.

[152] B.J. Johnson, E.G. Trask, 4-(methylthio)phenyl and 4-(methylsulfonyl)phenyl esters in the preparation of peptides and polypeptides. II. Synthesis of the protected heptapeptide (A82A88) of bovine chymotrypsinogen A, J. Org. Chem. 33(12) (1968) 4521-4524.

[153] B.J. Johnson, P.M. Jacobs, 4-(Methylsufonyl)phenyl Activated Ester. Susceptibility to Racemization. III, J. Org. Chem. 33(12) (1968) 4524-4526.

[154] J. Ulbricht, Insights into polymer biodegradation - Investigations on oxidative, hydrolitic and enzymatic pathways, Julius-Maximilians University Würzburg, Würzburg, 2017.

[155] Y.-C.M. Wu, T.M. Swager, Living Polymerization of 2-Ethylthio-2-oxazoline and Postpolymerization Diversification, J. Am. Chem. Soc. 141(32) (2019) 12498-12501.

[156] R. Zhang, W. Wu, Studies on the structures and interactions of glutathione in aqueous solution by molecular dynamics simulations and NMR spectroscopy, J. Mol. Liq. 162(1) (2011) 20-25.

[157] A. Tsutsui, Y. Morishita, H. Furumachi, T. Fujimoto, R. Hirai, T. Fujita, T. Machinami, Generation of cyclic glutathione via the thiolactonization of glutathione and identification of a new radical scavenging mechanism, Tetrahedron Lett. 68 (2021) 152836.

[158] K. Mitamura, N. Hori, S. Mino, T. lida, A.F. Hofmann, S. Ikegawa, Synthesis of the 3sulfates of S-acyl glutathione conjugated bile acids and their biotransformation by a rat liver cytosolic fraction, Chem. Phys. Lipids 165(3) (2012) 261-269.

[159] M. Glassner, S. Maji, R. Victor, N. Vanparijs, K. Ryskulova, B.G. De Geest, R. Hoogenboom, Solvent-free mechanochemical synthesis of a bicyclononyne tosylate: a fast route towards bioorthogonal clickable poly(2-oxazoline)s, Polym. Chem. 6(48) (2015) 83548359.

[160] G.G. Alvaradejo, M. Glassner, R. Hoogenboom, G. Delaittre, Maleimide endfunctionalized poly(2-oxazoline)s by the functional initiator route: synthesis and (bio) conjugation, RSC Adv. 8(17) (2018) 9471-9479.

[161] T.X. Viegas, M.D. Bentley, J.M. Harris, Z. Fang, K. Yoon, B. Dizman, R. Weimer, A. Mero, G. Pasut, F.M. Veronese, Polyoxazoline: Chemistry, Properties, and Applications in Drug Delivery, Bioconjugate Chem. 22(5) (2011) 976-986. 